\title{
Impact of solar versus volcanic activity variations on tropospheric temperatures and precipitation during the Dalton Minimum
}

\author{
J. G. Anet ${ }^{1}$, S. Muthers ${ }^{2,3}$, E. V. Rozanov ${ }^{1,4}$, C. C. Raible ${ }^{2,3}$, A. Stenke ${ }^{1}$, A. I. Shapiro ${ }^{4}$, S. Brönnimann ${ }^{5,3}$, \\ F. Arfeuille ${ }^{5,3}$, Y. Brugnara ${ }^{5,3}$, J. Beer ${ }^{6}$, F. Steinhilber ${ }^{6}$, W. Schmutz ${ }^{4}$, and T. Peter ${ }^{1}$ \\ ${ }^{1}$ Institute for Atmospheric and Climate Science ETH, Zurich, Switzerland \\ ${ }^{2}$ Climate and Environment Physics, Physics Institute, University of Bern, Bern, Switzerland \\ ${ }^{3}$ Oeschger Centre for Climate Change Research, University of Bern, Bern, Switzerland \\ ${ }^{4}$ Physikalisch-Meteorologisches Observatorium Davos and World Radiation Center (PMOD/WRC), Davos, Switzerland \\ ${ }^{5}$ Institute of Geography, University of Bern, Bern, Switzerland \\ ${ }^{6}$ Eawag, Surface Waters group, Dübendorf, Switzerland
}

Correspondence to: J. G. Anet (julien.anet@alumni.ethz.ch)

Received: 21 October 2013 - Published in Clim. Past Discuss.: 4 November 2013

Revised: 21 March 2014 - Accepted: 23 March 2014 - Published: 9 May 2014

\begin{abstract}
The aim of this work is to elucidate the impact of changes in solar irradiance and energetic particles versus volcanic eruptions on tropospheric global climate during the Dalton Minimum (DM, AD 1780-1840). Separate variations in the (i) solar irradiance in the UV-C with wavelengths $\lambda<250 \mathrm{~nm}$, (ii) irradiance at wavelengths $\lambda>250 \mathrm{~nm}$, (iii) in energetic particle spectrum, and (iv) volcanic aerosol forcing were analyzed separately, and (v) in combination, by means of small ensemble calculations using a coupled atmosphere-ocean chemistry-climate model. Global and hemispheric mean surface temperatures show a significant dependence on solar irradiance at $\lambda>250 \mathrm{~nm}$. Also, powerful volcanic eruptions in 1809, 1815, 1831 and 1835 significantly decreased global mean temperature by up to $0.5 \mathrm{~K}$ for 2-3 years after the eruption. However, while the volcanic effect is clearly discernible in the Southern Hemispheric mean temperature, it is less significant in the Northern Hemisphere, partly because the two largest volcanic eruptions occurred in the SH tropics and during seasons when the aerosols were mainly transported southward, partly because of the higher northern internal variability. In the simulation including all forcings, temperatures are in reasonable agreement with the tree ring-based temperature anomalies of the Northern Hemisphere. Interestingly, the model suggests that solar irradiance changes at $\lambda<250 \mathrm{~nm}$ and in energetic particle spectra have only an insignificant impact on the climate during the Dalton Minimum. This downscales the importance of top-down
\end{abstract}

processes (stemming from changes at $\lambda<250 \mathrm{~nm}$ ) relative to bottom-up processes (from $\lambda>250 \mathrm{~nm}$ ). Reduction of irradiance at $\lambda>250 \mathrm{~nm}$ leads to a significant (up to $2 \%$ ) decrease in the ocean heat content (OHC) between 0 and $300 \mathrm{~m}$ in depth, whereas the changes in irradiance at $\lambda<250 \mathrm{~nm}$ or in energetic particles have virtually no effect. Also, volcanic aerosol yields a very strong response, reducing the $\mathrm{OHC}$ of the upper ocean by up to $1.5 \%$. In the simulation with all forcings, the $\mathrm{OHC}$ of the uppermost levels recovers after 815 years after volcanic eruption, while the solar signal and the different volcanic eruptions dominate the $\mathrm{OHC}$ changes in the deeper ocean and prevent its recovery during the DM. Finally, the simulations suggest that the volcanic eruptions during the DM had a significant impact on the precipitation patterns caused by a widening of the Hadley cell and a shift in the intertropical convergence zone.

\section{Introduction}

The Dalton Minimum (DM) was a 60 year-long period of low solar activity, lasting from AD 1780 to 1840. In addition, early in the 19th century, two major volcanic eruptions took place, injecting large amounts of sulfur dioxide into the stratosphere, which, after conversion to sulfate aerosols, increased planetary albedo, affecting the global climate. In 1816 , an exceptionally cold summer was recorded in Western 
Europe. This year became known as the "year without summer" (Harington, 1992; Robock, 1994). While the scientific acceptance of a significant climate impact from volcanic eruptions is high, there is ongoing debate about the contribution of the solar variability to global temperature changes in the troposphere during the DM; see for example Table 2.11 of the IPCC AR4 (IPCC, 2007).

It is well known that solar activity varies over time. This is not only documented by the sunspot number data sets (Wolf, 1861), but also by the ${ }^{10} \mathrm{Be}$ cosmogenic isotopes conserved in ice sheets (Steinhilber et al., 2008, 2009). The past evolution of the solar irradiance has been reconstructed by a number of authors (see Solanki et al., 2013, and references therein). Recently, Shapiro et al. (2011) reconstructed the spectral solar irradiance (SSI) for the last 400 years using the solar modulation potential $\Phi$ as a proxy. Their results show that the decrease in the heavily absorbed UV-C during the DM reaches $15 \%$, while it does not exceed $1 \%$ in the solar spectrum with $\lambda>250 \mathrm{~nm}$ and is negligible in the solar near infrared (NIR). This disproportionate change in the spectral solar irradiance has complex effects on the Earth's atmospheric chemistry and climate system: on one hand, a substantial decrease in the UV-C at $\lambda<250 \mathrm{~nm}\left(0.3 \mathrm{~W} \mathrm{~m}^{-2}\right)$ cools down the middle atmosphere and decreases the ozone production due to decelerated oxygen photolysis (Anet et al., 2013), resulting in a very small radiation anomaly on the Earth's surface. On the other hand, the decrease at $\lambda>250 \mathrm{~nm}$ by $6.5 \mathrm{~W} \mathrm{~m}^{-2}$ does not affect stratospheric chemistry, but directly influences surface temperatures.

A negative UV-C anomaly affects the state of the stratosphere and mesosphere (Rozanov et al., 2012a; Anet et al., 2013), from where it may influence the troposphere via a cascade of mechanisms: by cooling down the tropical and midlatitude stratosphere, it decreases the pole-to-equator temperature gradient, weakens the zonal winds and accelerates the Brewer-Dobson circulation. The latter is followed by a cooling in the lower tropical stratosphere (Kodera and Kuroda, 2002), and a subsequent modulation of the Hadley cell (Haigh, 1996) impacting especially the equatorial region and alteration of the tropospheric wave pattern (Brugnara et al., 2013), propagating down to the surface. This is also known as the top-down mechanism (Meehl et al., 2009). However, in the present set of simulations the top-down mechanism is shown to be of minor importance when compared with other mechanisms discussed below.

Complementary to the top-down mechanism is the "bottom-up" mechanism, which we investigate here by separating the role of solar irradiance at $\lambda>250 \mathrm{~nm}$ : as most of this radiation is able to pass through the stratosphere without major absorption, its anomalies directly impact the radiation fluxes, energy balance and temperatures on the ground. Depending on the surface albedo, a part of this radiation is absorbed and transformed into latent or sensible heat. During periods with weak solar activity, less radiation is available in the tropics for conversion to latent heat, which is thought to lead to a decrease in the amount of precipitation (Meehl et al., 2008) and thus a weakening of the Ferrel and Hadley cells (Labitzke et al., 2002). Both mechanisms thus finally influence the atmospheric circulation, differentiable by the time at which and where they start to influence the atmosphere. Generally, one can say that the top-down effect essentially starts to influence polar regions in hemispheric winter time, whereas the bottom-up effect literally can influence especially tropical regions during the entire year.

Besides electromagnetic radiation, a second major factor varying over time and influencing stratospheric and upper tropospheric chemistry and - regionally - tropospheric dynamics is energetic particle precipitation (EPP). These particles consist of galactic cosmic rays (GCRs), solar energetic particles (SEPs), low energy electrons (LEE) originating from the magnetosphere and high energy electrons (HEE) stemming from the Earth's radiation belt. While SEP and LEE/HEE vary in phase with the solar activity, GCRs are partly deflected by the solar wind, and therefore are negatively correlated with solar activity. Ionization of neutral molecules like $\mathrm{N}_{2}$ or $\mathrm{O}_{2}$ by energetic particles facilitates the formation of $\mathrm{NO}_{\mathrm{x}}$ and $\mathrm{HO}_{\mathrm{x}}$ (see, e.g., Sinnhuber et al., 2012), accelerating the ozone destruction followed by a cooling inside the polar vortex and an increase in pole-to-equator temperature gradients, which in turn can change the tropospheric climate. These processes were simulated by several chemistry-climate models (CCM) and a significant response of the atmosphere to EPP was identified (Calisto et al., 2011; Semeniuk et al., 2011; Rozanov et al., 2012b). However, in our previous study (Anet et al., 2013) the net effect of particles was found to be rather weak. This is seemingly contradictory, but can be partly explained by a compensating effect of decreasing LEE and increasing GCR intensity during the DM, which above-mentioned studies could not take into account because they either investigated only one sort of the energetic particles, or they compared model runs with all EPP included against a reference run without any EPP.

A third factor, which notably influenced the stratospheric and tropospheric climate and chemistry, at least for a short time in the DM, are major volcanic eruptions, which are known for having ejected up to $60 \mathrm{Mt}$ (Tambora volcanic eruption, year 1815, Gao et al., 2008) of sulfur dioxide into the atmosphere. Presumably, the plumes reached deep into the stratosphere, where the massive amounts of sulfur dioxide were converted to sulfate aerosols. As a result, the haze in the sky and colorful sunsets were reported during the period (see, e.g., Olson et al., 2004). The aerosol particles efficiently scatter a fraction of the incoming solar radiation back into space, but also absorb a part of the outgoing terrestrial infrared (IR) and incoming solar near IR (NIR). The reduction in incoming visible or NIR radiation overwhelms the IR absorption, leading to an overall global cooling, except in the polar night, where sunlight is lacking and a small warming prevails (Robock, 2000). Generally, a significant cooling of the surface occurs in the first weeks after major 
volcanic eruptions, lasting for one to two years and being associated with modified patterns of precipitation, surface pressure and the teleconnection patterns, such as the Arctic Oscillation (AO), North Atlantic Oscillation (NAO) (Shindell et al., 2000; Stenchikov et al., 2002; Fischer et al., 2007) or the El Niño-Southern Oscillation (ENSO) (Robock and Mao, 1995; Adams et al., 2003), due to the downward propagation of positive anomalies in the stratospheric polar vortex strength.

Different modeling studies in the recent past show a large range of simulated climate responses to solar forcings. For instance, Wagner and Zorita (2005) showed with an atmosphere-ocean general circulation model (AO-GCM) without coupled chemistry that the combined effects of volcanic eruptions and solar irradiance decrease could significantly (by up to several tenths of a degree) modify global mean temperatures. They attributed most of this cooling to the volcanic effects, and their "solar-only" simulation without volcanic eruptions showed a decrease in global temperatures of only $0.1 \mathrm{~K}$. Feulner (2011) concluded from his experiment with an intermediate complexity model that the solar contribution to the cool period during the DM was likely a smaller one. They showed that the cold climate was explained mostly by volcanic forcing. Their application of the strong solar irradiance forcing proposed by Shapiro et al. (2011) led to a substantial disagreement between their simulated and reconstructed temperature time series. Shindell et al. (2000) compared the long-term influence of volcanic eruptions to grand solar minimum conditions with a focus on the DM and on the Maunder Minimum (MM) - which occurred about $150 \mathrm{yr}$ before the DM. Unfortunately, the exact solar forcing used for their modeling study remains unknown, but they concluded that volcanic eruptions have rather strong but only short-lived effects on temperatures, while the reduction of the solar irradiance during the grand minimum affects temperatures on longer timescales. They estimated a solar-induced cooling during the MM of 0.6 to $0.8 \mathrm{~K}$ globally. For the same period, Varma et al. (2012) investigated the Southern Hemispheric wind field response to the MM solar irradiance decrease. They estimated the stratospheric ozone change due to the reduction of solar UV irradiance from a global scaling with total solar irradiance (TSI) variations, which could lead to a shift in the Southern Hemispheric westerly winds to the north via the "top-down" mechanism consisting of a chain of complex radiative-dynamical processes (Meehl et al., 2008; Haigh, 1996). In another paper, Varma et al. (2011) concluded that the "bottom-up" mechanism via a reduction of visible irradiance had a similar effect. However, these publications (Varma et al., 2011, 2012) do not provide detailed information on changes in tropospheric temperatures. Zanchettin et al. (2013) investigated the decadal response change of the 1815 Tambora volcanic eruption to different background climate states. They found a significant dependence on background conditions when looking at ocean dynamics, especially concerning heat transport and sea ice in the North Atlantic region.

The influence of volcanic and solar forcing on ozone chemistry, stratospheric temperatures and global circulation has become of great scientific interest in the recent years. The aim of this work is to analyze the tropospheric climate changes during the DM with a fully coupled atmosphereocean chemistry-climate model (AO-CCM) driven by the state-of-the-art set of climate forcings and to disentangle the contributions from changes in solar spectral irradiance, energetic particles and volcanic eruptions. To the best of our knowledge so far, such a sophisticated model and climate forcing set have not been applied for the evaluation of the tropospheric climate changes during the DM.

The work is structured as follows: after Sect. 1, which has described the state of the research and introduced some notation, Sect. 2 will provide a description of our model and our experiments. Section 3 focuses on the changes in surface temperatures and precipitation patterns caused by the different forcings. We further compare our model results to reconstructed temperature fields, and conclude in Sect. 4.

\section{Sensitivity experiments and model description}

\subsection{AO-CCM SOCOL3-MPIOM}

The AO-CCM SOCOL3-MPIOM emerges from a modification of CCM SOCOL version 3 (Stenke et al., 2013), which has been coupled with the OASIS3 coupler (Valcke, 2013) to the Max Planck Institute ocean model (MPIOM, Marsland et al., 2003). SOCOL3 is based on the GCM ECHAM5 (Roeckner et al., 2003) and includes the chemical part of the MEZON chemistry-transport model (Rozanov et al., 1999; Egorova et al., 2003; Schraner et al., 2008). SOCOL3-MPIOM is applied in middle atmosphere mode (MA) extending from the ground to $0.01 \mathrm{hPa}$ or around $80 \mathrm{~km}$. Simultaneously with the radiation calculation, MAECHAM5 hands over temperature fields to MEZON, which takes into account interactions between 41 gas species - including 200 gas phase, 16 heterogeneous and 35 photolytic reactions. Those chemical fields are then handed back to MA-ECHAM5, which calculates all components of the general circulation and tracer advection.

All simulations have been executed using the model version with T31L39 resolution, which equals an average horizontal grid space of $3.75^{\circ}(\sim 400 \mathrm{~km})$ and an irregularly spaced vertical resolution of 39 levels. Due to the relatively coarse vertical resolution, the quasi-biennial oscillation is not reproduced autonomously. Hence, the equatorial zonal wind fields are nudged to reconstructed zonal mean wind data sets as in Giorgetta (1996).

It is known that the original MA-ECHAM5 code does not properly take into account radiative absorption by oxygen, either in the Lyman-alpha line or in the Schumann-Runge 

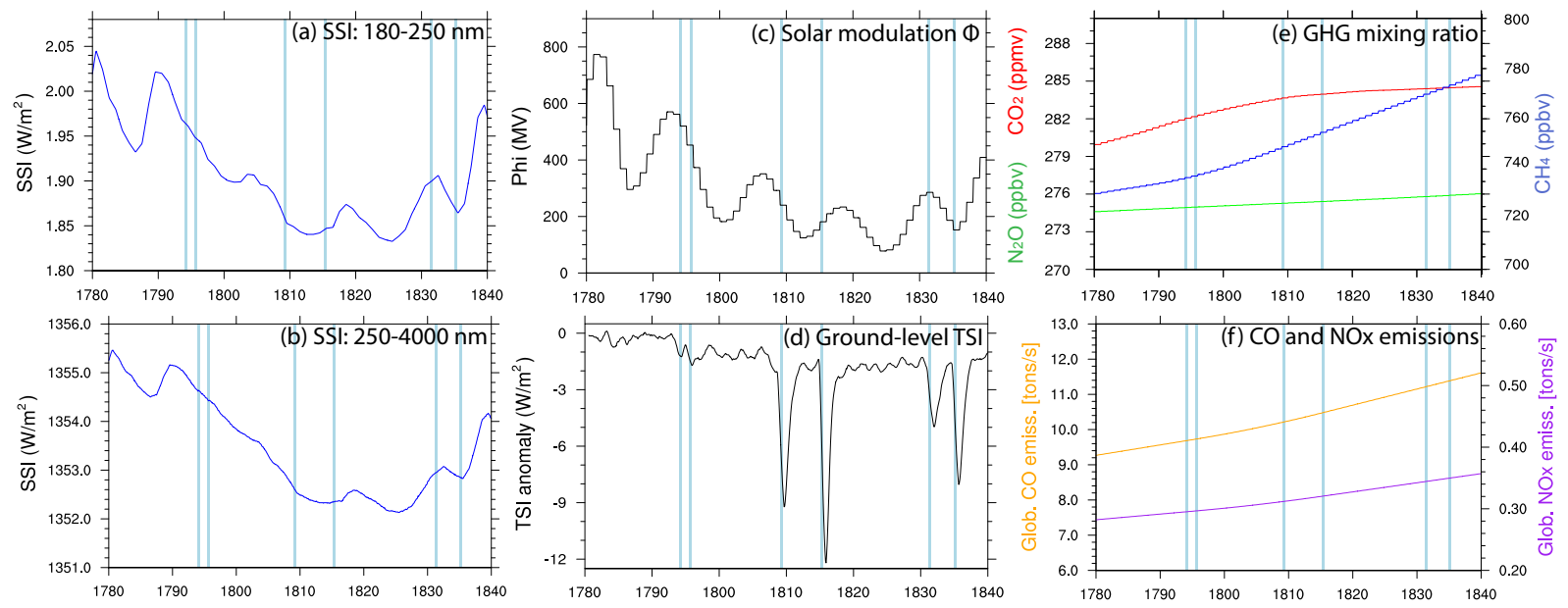

Fig. 1. Model forcing data over the Dalton Minimum (AD 1780-1840). (a) Spectral solar irradiance in the UV-C at $180 \mathrm{~nm}<\lambda<250 \mathrm{~nm}$. (b) Spectral solar irradiance at $\lambda>250 \mathrm{~nm}$. (c) Solar modulation potential following Steinhilber et al. (2008). (d) Ground-level TSI, showing anomalies relative to the 1780 unperturbed values. (e) Greenhouse gas mixing ratios for $\mathrm{CO}_{2}, \mathrm{CH}_{4}$ and $\mathrm{N}_{2} \mathrm{O}$. (f) Anthropogenic and natural $\mathrm{CO}$ and $\mathrm{NO}_{\mathrm{x}}$ emissions from fossil fuel burning. Blue vertical lines highlight the years in which a volcanic eruption occurred.

bands, and the absorption of ozone in the Hartley or Huggins bands is also only coarsely resolved (Forster et al., 2011). Hence, the heating rate calculation has been improved to add the missing parts following the approach of Egorova et al. (2004) adapted to the spectral resolution of the ECHAM5 radiation code. The parameterizations for the ionization rates by GCR, SEP and LEE were introduced identically as in Rozanov et al. (2012b) and Anet et al. (2013). HEE are not implemented due to the absence of an easily applicable parameterization.

The ocean is run in GR30 resolution (nominal resolution of around $3^{\circ}$ ). Its north pole is displaced to Greenland, making it possible to raise the resolution in the North Atlantic basin. The applied version of the AO-CCM SOCOL3MPIOM and its performance in the representation of the climate evolution is presented by Muthers et al. (2014b).

\subsection{Boundary conditions}

The applied boundary conditions are described in detail by Anet et al. (2013). As a summary, the most important forcings are recapitulated subsequently.

The forcing caused by spectral solar irradiance changes is based on the mean values of the reconstruction by Shapiro et al. (2011), as illustrated in Fig. 1a and b. This determines the photolysis and heating rates due to solar irradiance absorption by various air components. Shapiro et al. (2011) assumed that the minimum state of the quiet Sun corresponds to the observed quietest area on the present Sun, and then used available long-term proxies of the solar activity (i.e., ${ }^{10} \mathrm{Be}$ isotope concentrations in ice cores, 22 year smoothed neutron monitor data) to interpolate between the present quiet Sun and the minimum state of the quiet Sun. This determines the long-term trend in the solar variability, onto which the
11 year activity cycle calculated from the sunspot number is then superposed. The time-dependent solar spectral irradiance is derived using the COSI state-of-the-art radiation code (Shapiro et al., 2010). The resulting spectral solar irradiance of this reconstruction is substantially lower during the MM than the one observed today, and the difference is larger than in the other recently published estimates. The advantage of this high-amplitude reconstruction is that it allows us to derive a maximum conceivable terrestrial climate response to solar changes, while other reconstructions leave hardly any fingerprint on the modeled climate.

For the EPPs, the $A_{p}$ index reconstruction from Baumgaertner et al. (2009) is used for the LEE. For SEPs, return period-based data sets were created from an analysis of the last 45 years of the last century. The GCR ionization rates depend on the solar modulation potential $\Phi$ (Fig. 1c), which was reconstructed by Steinhilber et al. (2008). The geomagnetic dipole field strength and position are provided from paleomagnetic data sets from Finlay et al. (2010).

The volcanic forcing is based on simulations carried out with a 2-D aerosol microphysical model (Arfeuille et al., 2014). It uses total aerosol injection values from Gao et al. (2008) and information on the date/location of each eruption. The stratospheric aerosols are prescribed in terms of extinction ratios, single scattering albedos and asymmetry factors for each of the 22 ECHAM5 radiation bands and in terms of surface area densities, for each latitude-altitude band of SOCOL (zonally averaged). Aerosol optical depth values derived from this forcing are documented in Table 1. The globally averaged effect on incoming surface shortwave radiation is shown in Fig. 1d, and shows higher anomalies than that of Crowley (2000) or Robertson et al. (2001). 
Table 1. Stratospheric aerosol optical depths at $550 \mathrm{~nm}$ derived from volcanic aerosol simulations (Arfeuille et al., 2014) using ice core measurements from Gao et al. (2008).

\begin{tabular}{cccl}
\hline & \multicolumn{2}{l}{ Aerosol optical depth } & \\
\cline { 2 - 3 } Year & $\mathrm{NH}$ & $\mathrm{SH}$ & Volcano, confirmed/tentative attrib. \\
\hline 1794 & 0.02 & 0.04 & Unknown SH, no large eruption recorded \\
1796 & 0.12 & 0.02 & Unknown NH, no large eruption recorded \\
1809 & 0.12 & 0.42 & Unknown Tropics, eruption in February \\
1815 & 0.24 & 0.68 & Tambora $8^{\circ} \mathrm{S}$, Indonesia, 10 April \\
1831 & 0.22 & 0.06 & Babuyan Claro $19.5^{\circ} \mathrm{N}$, Philipp., date? \\
1835 & 0.36 & 0.23 & Cosiguina $13^{\circ} \mathrm{N}$, Nicaragua, 20 January \\
\hline
\end{tabular}

The QBO was generated by means of a backwards extension of an already existing reconstruction, using an idealized QBO cycle that is superimposed onto the regular seasonal cycle (Brönnimann et al., 2007).

The greenhouse gas forcings (Fig. 1e) for the period from 1780 to 1840 are based on the PMIP3 protocol (Etheridge et al., 1996, 1998; Ferretti et al., 2005; MacFarling-Meure et al., 2006; Meehl et al., 2009), while halogens are kept constant at preindustrial levels. The standard ECHAM5 land surface data sets by Hagemann et al. (1999) and Hagemann (2002) are used. Tropospheric aerosol fields were extracted from existing CAM3.5 simulations driven by CCSM3 (CMIP3) sea-surface temperatures and 1850-2000 CMIP5 emissions. These fields were then scaled as a function of the world population starting in the year 1850 going backwards, except for the $10 \%$ (relative to the 1990 values) of biomass burning, which were considered constant over time.

For the global $\mathrm{CO}$ and $\mathrm{NO}_{\mathrm{x}}$ emissions, the part emitted from shipping was calculated starting from the CMIP5 data sets, which were projected linearly backwards from 1850 on to the year 1800 . Before 1800 , no steamships existed, thus these emissions were set to zero. The natural biomass burning emissions were assumed to be constant over time, while the anthropogenic biomass burning emissions were scaled with the world population. The emissions are illustrated in Fig. 1f.

\subsection{Sensitivity experiments}

We performed six sensitivity experiments covering the time period from 1780 to 1840 (Table 2), each with three ensemble members. The simulations, identical to those described by Anet et al. (2013), were initialized from a long transient model run covering AD 1600-2100. The disturbances were introduced by starting the sensitivity study simulations from an ocean state one year "older" and one year "younger" than December 1779, as the time frames of December 1778, December 1779 and December 1780 provided a good mix between weak El Niño or La Niña conditions, avoiding extreme conditions in the oceanic signal (El Niño 3.4 indexes: -0.9 for December 1778 , +0.8 for December 1779 and +0.6 for December 1780 of the "mother
Table 2. Dalton minimum experiments: "const" denotes constant 1780 conditions. "bckgrd" denotes background aerosol emissions and volcanic emissions off. "trans" denotes transient forcing. "Ioniz." stands for the parametrization for SPE, LEE and GCR.

\begin{tabular}{lllll}
\hline \multirow{2}{*}{ Experiment } & \multicolumn{4}{c}{ Process } \\
\cline { 2 - 5 } name & $\Delta I$ & $\Delta I$ & $\Delta$ Ioniz. & $\Delta \mathrm{SAD}$ \\
& $(\lambda<250 \mathrm{~nm})$ & $(\lambda>250 \mathrm{~nm})$ & & \\
\hline CTRL1780 & const & const & const & bckgrd \\
ALL & trans & trans & trans & trans \\
TD & trans & const & const & bckgrd \\
BU & const & trans & const & bckgrd \\
EPP & const & const & trans & bckgrd \\
VOLC & const & const & const & trans \\
\hline
\end{tabular}

run"). The nomenclature is as follows: the run including all effects acting together on the climate system is named ALL. The "Top-Down" (TD, Meehl et al., 2008) sensitivity experiment includes only the variations of solar irradiance with $\lambda<250 \mathrm{~nm}$ and the corresponding extra heating (corrections for the Lyman- $\alpha$ line, the Schumann-Runge, Hartley and Huggins bands) and photolysis rates of photolytic chemical reactions. The "Bottom-Up" (BU) experiment (Meehl et al., 2008) allows only irradiance $\lambda>250 \mathrm{~nm}$ to vary over time. The EPP experiment is exclusively forced by energetic particles. In the VOLC experiment, all other forcings except the stratospheric aerosols, which affect the radiation budget and heterogeneous chemistry via changes in surface area density (SAD), were kept constant. All runs were compared to a 60 year-long control run with three ensemble members with perpetual 1780 conditions called CTRL1780. The analysis of the data was done by comparing zonally and temporally averaged ensemble mean fields to the CTRL1780 ensemble mean.

In order to focus on the strongest signals (and following Anet et al., 2013), the period from 1805 to 1825 is chosen for the temperature, precipitation and mass stream function analysis showing regional patterns on latitude-longitude or latitude-height plots, thus reducing the signal-to-noise ratio. Time evolution plots of the temperatures and ocean heat content show ensemble means of the entire simulation period. Oceanic as well as surface temperature data have been smoothed with an 12 month full width-half maximum (FWHM) Gaussian filter. The statistical significance of the global distribution of the $2 \mathrm{~m}$ temperature anomalies was computed using a 2-sample Student's $t$ test across all $3 \times 20=60$ data points, as was done in Anet et al. (2013) on a $5 \%$ significance level, taking autocorrelation into account. The latter was done by calculating the number of independent data points over the $3 \times 20$ time steps. The statistical analysis of the hydrological cycle was done similarly, with the exception that the significance level was set to $10 \%$ (surface temperature volcanic anomalies, precipitation, mass stream function). 


\section{Results}

First, we discuss regional temperature differences between the specific sensitivity experiment and the CTRL1780 experiment averaged over the AD 1805-1825 period. Then we present the contribution of different forcing factors to the evolution of the mean surface temperature and ocean heat content during the entire integration period. Finally, changes in the precipitation are described in Sect. 3.3.

\subsection{Temperature}

The regional pattern of the annual mean $2 \mathrm{~m}$ temperature difference between the ALL and the CTRL1780 simulation is illustrated in Fig. 2a. In particular, the tropical and subtropical regions undergo a significant cooling by values ranging from 0.2 to $1 \mathrm{~K}$. The cooling is more pronounced over the land masses than over the oceans. Three small positive temperature anomalies appear over the Bering Sea, the western Antarctic, and over the northern Atlantic regions. Significant deviations from the annual mean figure are a strong cooling during Northern Hemispheric (NH) winter over Siberia and Alaska, as well as the significant warming during polar winter over the respective polar hemisphere (Fig. S1 in the Supplement).

The cooling of the continents can be explained by the BU experiment shown in Fig. 2b, which simulates cooling patterns similar to the ALL ensemble mean, except over northern Asia and parts of Europe. The cooling is caused by the negative anomaly in solar irradiance at wavelengths $\lambda>250 \mathrm{~nm}$ and subsequently by a reduced heating of the surface. The weaker ocean response is related to the large heat capacity of the ocean, partly compensating the reduced irradiance.

The slight warm anomalies over the Bering Sea and western Antarctic Peninsula regions can be explained with the VOLC simulation (Fig. 2c). The warming pattern over the Bering Sea region, triggered by ocean upwelling (see later) is present during the whole year. In the western Antarctic Peninsula and North Atlantic regions, the patterns are predominant during the SH winter season (JJA). The western Antarctic Peninsula warming is associated with an enhanced transport of milder air masses from the subtropics, leading to a slight but significant sea ice melting (not shown). This is related to differential temperature anomalies from absorption and/or reflection of radiation by the volcanic aerosols, as shown in Anet et al. (2013). The major warming over the Bering Sea originates from a strengthening of the northward surface winds inducing a positive meridional wind stress anomaly above the northwestern Pacific and the opposite namely a weakening of the northward surface winds inducing a negative anomaly of the meridional wind stress - in the northeastern Pacific region (not shown). This facilitates ocean upwelling via the Ekman mechanism in this region, where deep water upwelling prevails (oceanic conveyor belt).
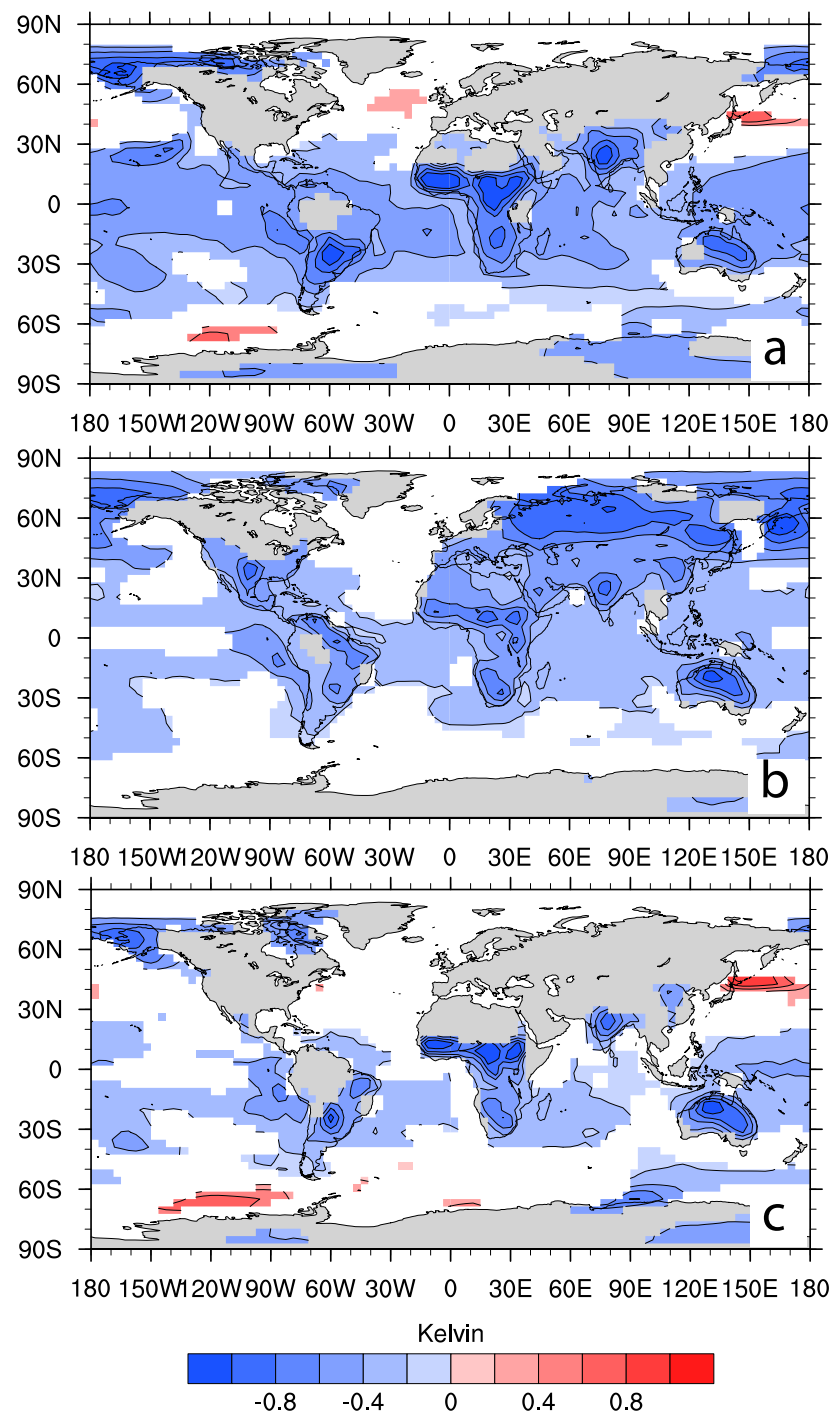

Fig. 2. (a) Ensemble mean of $2 \mathrm{~m}$ temperature differences, averaged over the 1805-1825 period for the ALL run. (b) Same for the "Bottom-Up" run. (c) Same for the VOLC run. Only areas that are significant at the $5 \%$ level are colored (two-sided $t$ test).

The surface water of the northern Bering Sea region, cooling down during the winter season, is replaced by deeper, older water from the thermocline region, which has no imprint of the volcanic signal yet, as indicated by a slight increase in the modeled vertical ocean mass transport in the winter season in that region. The warming signal is so strong that it persists throughout the year. The same warm anomaly was also found by Wang et al. (2012), which explained the finding by weakening surface westerly winds due to a strengthening polar vortex. Forming a positive surface pressure anomaly, net heat fluxes and ocean advection in the Northern Pacific region are modified. Although corroborative, these results should be confirmed by using a higher number of ensemble members to ensure its robustness, which would go beyond the scope 
of this work. Both the BU and the VOLC simulations show a slight but not significant warming over the North Atlantic. One might speculate that the warming pattern shown in ALL results from a combination of volcanic and solar influences, although certain nonlinearities prohibit the direct comparison of BU+VOLC and ALL, as was already shown in Anet et al. (2013). Moreover, as illustrated in Fig. S2 in the Supplement, the response in the $\mathrm{AMOC}$ is relatively weak in $\mathrm{BU}$, while a distinct increase in the AMOC is visible in VOLC. This finding agrees well with the work of Zanchettin et al. (2013), which finds a significant increase of $0.6 \mathrm{~Sv}$ in the AMOC after Tambora, while we find a significant increase of up to $1 \mathrm{~Sv}$ after both volcanic eruptions (beginning of the 1820 s minus the pre-volcanic era). We do not find any additive effect of both eruptions, which could mean that a certain saturation effect might stop the acceleration of the AMOC. This finding however should be investigated in more detail in a future work.

The TD experiment does not reveal any statistically significant temperature anomalies either in the yearly or in the seasonal means (not shown). The EPP forcing does not produce any annual mean response; however, a strong winter warming pattern is simulated during the boreal winter over the northern polar regions (see Fig. S3 in the Supplement). The temperature response for the EPP case is much weaker and appears in a completely different location than in the previous studies (e.g., Calisto et al., 2011; Rozanov et al., 2012b). This can be explained by the fact that our EPP experiment is designed in a significantly different way: while in Calisto et al. (2011) and Rozanov et al. (2012b), the sensitivity study was done by comparing a simulation with enabled EPP parameterization to a simulation with disabled EPP parameterization, we compare a simulation with transient EPP to a simulation with constant 1780 EPP forcing. Hence the decreasing SEP and LEE ionization rates might compensate for the effect of increasing GCRs.

Compared to the climate simulations of Calisto et al. (2011) or Rozanov et al. (2012b), the lower amplitude of the simulated anomalies is attributed to a different stratosphere-troposphere coupling behavior from SOCOL3MPIOM, whose atmospheric transport model is based on ECHAM5, compared to SOCOL2, based on ECHAM4. Especially the winter polar vortex represents a key factor determining how stratospheric influences can propagate down into the troposphere. Stratospherically induced disturbances in the polar vortex may lead to short-lived vortex breakdowns, facilitating the advection of warmer air masses from the midlatitudes into higher latitudes at the surface. There, surface warm anomalies are the consequence. In both the beforementioned works, strong warm $2 \mathrm{~m}$ temperature anomalies were found during the winter season over Europe and western Asia. This finding cannot be confirmed with our modeling results, which show a small, but significant warming over the polar region. The exact reason of this different behavior has not yet been found, but it may originate in the weaker winter vortex in SOCOL3-MPIOM. Muthers et al. (2014a) showed that the downward propagation depends on the state of the polar vortex and can be underrepresented if the polar vortex is too weak. The deficiency is confirmed by the lack of any significant temperature response to the TD and EPP signal over Europe - which could possibly be improved by modifying the gravity wave parameterization in ECHAM5.

In agreement with Robock and Mao (1992), Kirchner et al. (1999), and Driscoll et al. (2012), or with the DM analysis of Fischer et al. (2007), we discern a slight, yet significant winter warming pattern (WWP) over Europe, Russia and parts of North America in the years following the volcanic eruptions (Fig. 3b) and a weak cool anomaly during the summer seasons following the volcanic eruptions (Fig. 3a). The signal most probably due to a too weak representation of the topdown mechanism during volcanic eruptions is weaker than in the aforementioned studies. The warming in DJF is caused by a slight shift of the NAO to a NAOplus-like phase, enhancing the mid-latitude westerlies (see Fig. 3d) and influencing the precipitation patterns (see later). The axis of the NAO pattern is slightly tilted counterclockwise (see climatology in Fig. S4 in the Supplement).

We now focus on the temporal evolution of the temperature anomalies during the DM (Fig. 4). For these illustrations, values of the CTRL1780 experiment were subtracted from the ALL, VOLC and BU time series. The internal variability of CTRL1780 is relatively small ( $\sigma$ global, annual ensemble mean $(\mathrm{AEM})=0.095 \mathrm{~K}, \sigma \mathrm{NH}$ AEM $=0.154 \mathrm{~K}$, $\sigma \mathrm{SH}$ AEM $=0.099 \mathrm{~K})$.

Compared to CTRL1780 the ALL experiment (Fig. 4a) shows a significant decrease in global mean temperatures starting in 1809. After the temperature minimum following the Tambora eruption (1815), the modeled temperatures show a slight recovery, but do not completely reach unperturbed conditions. After 1830, a second decrease in temperatures follows. We note that before 1809 , all experiments show a very similar temperature evolution and that the strong volcanic eruptions $(1809,1815,1831$ and 1835) cause a clear excursion to low temperatures. These signals are clearly visible in the ocean heat content (Fig. 4b). Again, four shortterm reductions in the ALL run can be recognized after the volcanic eruptions, however, with a delay of 2 to 4 years due to the thermal inertia of the ocean. Until 1830 the SH mean temperature evolution (Fig. 4c) is very similar to the global mean. However, the volcanic eruptions after 1830 have a smaller influence on SH temperatures, as the Babuyan Claro (1831) and Cosiguina (1835) eruptions are of a smaller size than the 1809 and 1815 eruptions and are also characterized by a higher aerosol loading in the NH than in the SH. Due to the smaller direct aerosol forcing and to the much higher internal variability of the climate system in the $\mathrm{NH}$ than in the $\mathrm{SH}$, the cooling signal after 1809 is far more difficult to recognize in Fig. 4d. However, a significant decrease in temperatures of the ALL experiment is simulated after 1815 as well as a second dip to lower temperatures drop after 1830 . 

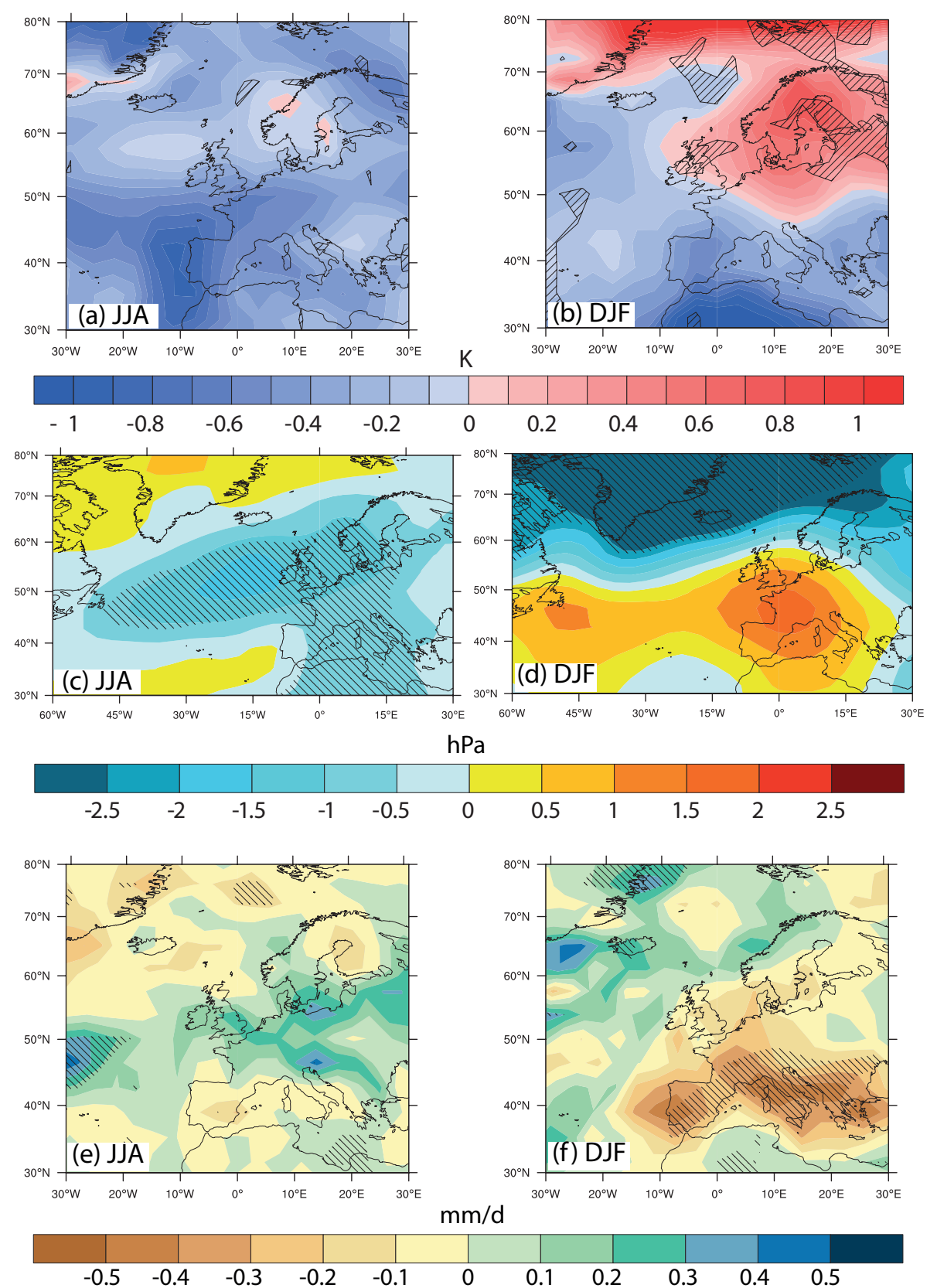

Fig. 3. Ensemble mean of post-volcanic surface temperature $(\mathbf{a}, \mathbf{b})$, sea level pressure $(\mathbf{c}, \mathbf{d})$ and precipitation $(\mathbf{e}, \mathbf{f})$ anomalies, showing the difference between VOLC (4 years: 1810, 1816, 1832 and 1836) and CTRL1780 ( $3 \times 60=180$ years) in the JJA (left panels) and DJF (right panels) season. For all plots, dashed areas show significant changes in a $10 \% t$ test (two-sided $t$ test).

The cooling after 1809 can be partially explained by the volcanic eruptions of 1809, 1815, 1831 and 1835 . The green curve in Fig. $4 a$ and $b$ of the VOLC experiment shows negative excursions at exactly those years. However, a clear recovery to pre-1809 temperatures is simulated after 1817 . The next decrease in temperatures appears only after the 1831 volcanic eruption. Focusing on the volcanic response a clear inter-hemispheric difference is found: while in the $\mathrm{SH}$, especially the 1809 and 1815 volcanic eruptions are well visible; the NH seems to be more responsive to the 1831 and 1835 volcanic eruptions. This is consistent with the different stratospheric aerosol loading. The temperature increases in the NH from 1813 to 1820 back to unperturbed temperature levels - and even positive anomalies in the 1820 s - represent a supercompensation-like feature simulated by our model after each strong volcanic eruption. As will be shown later, this warm anomaly pattern is caused by oceanic influence, a finding that agrees with a similar study by Zanchettin et al. 

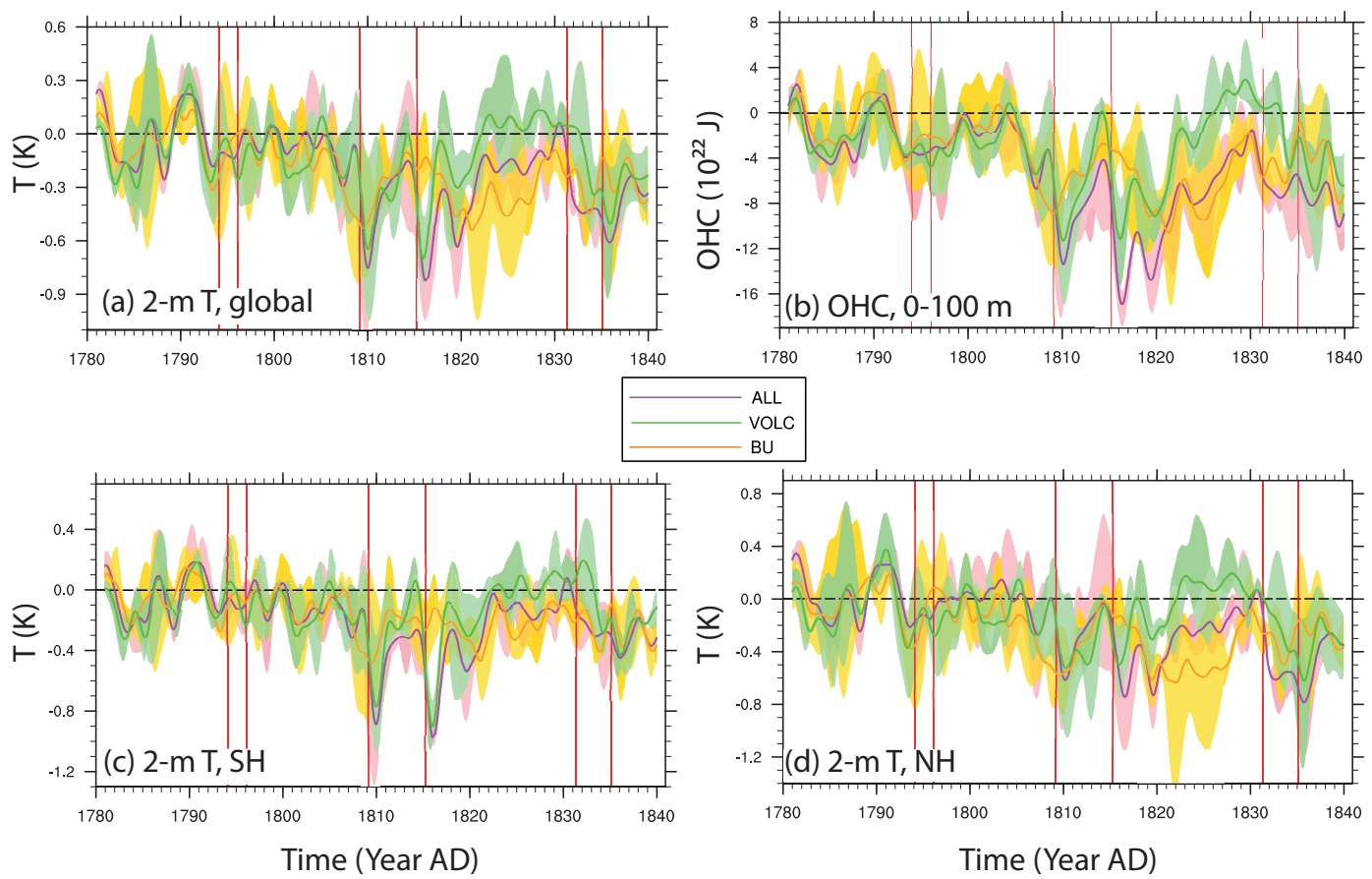

ALL
VOLC
BU

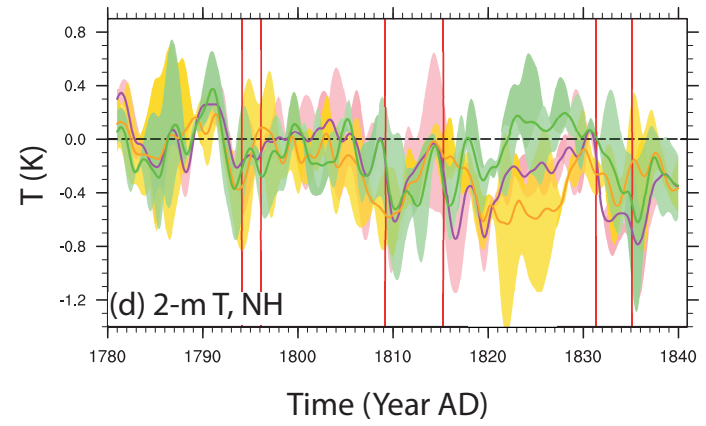

Fig. 4. (a) Ensemble means of detrended anomalies of experiments ALL, VOLC and BU relative to CTRL1780 for (a) global $2 \mathrm{~m}$ temperatures; (b) global ocean heat content (OHC) of the upper ocean (first $100 \mathrm{~m}$ in depth); (c) SH $2 \mathrm{~m}$ temperatures; (d) NH $2 \mathrm{~m}$ temperatures. For all experiments, the envelope shows the $\mathrm{min} / \mathrm{max}$ values. Red vertical lines highlight the years in which a volcanic eruption occurred.

(2012). The short-term warming right after preindustrial volcanic eruptions can be explained by a small, but significant increase in tropospheric ozone concentrations after the volcanic eruptions, acting as a greenhouse gas. This increase in ozone is related to a reduction in the production rate (less radiation, less water vapor) of the hydroxyl radical $\mathrm{OH}$, which is a very efficient factor in the ozone destruction. This increase is especially pronounced over the $\mathrm{NH}$ due to larger $\mathrm{CO}$ concentrations.

In order to explain the rather low temperatures of ALL between 1817 and 1830, an additional mechanism to the volcanic eruptions only has to be considered: the BU ensemble mean in Fig. 4a and b describes a negative anomaly in temperatures and $\mathrm{OHC}$ from 1808 on. Those below-normal conditions persist until the year 1839 , and are by far stronger in the NH (Fig. 4d) than in the SH (Fig. 4c) due to a greater number of land masses. Our model results even suggest an unprecedented cool period in the NH in the 1820s following the BU scenario. This period would even have been colder than the simulated and reconstructed (see later) postTambora era (1816-1818), hence pointing to the importance of the volcanic eruptions during the DM, which interfered with the solar-only forcing effects.

In the ocean, a downward propagation of the signal from shallow to more deep layers is illustrated in Fig. 5a-c. While neither radiation with $\lambda<250 \mathrm{~nm}$ nor EPP (Fig. S5 in the Supplement) seems to influence the ocean heat content significantly on any level, the radiation with $\lambda>250 \mathrm{~nm}$
(Fig. 5b) and volcanic (Fig. 5c) signals propagate down to deeper ocean layers. In Fig. 5a, we note that while the upper layers (green curves) still show a small recovery after the volcanic eruptions, taking around 5-8 years, there is no signal of recovery in the deep ocean (black curves) during the DM period. Moreover, on one hand, the bottom-up signal (Fig. 5b) takes more time to influence the ocean heat content in deeper layers than the volcanic eruptions (Fig. 5c), which is due to the lower net irradiance anomaly in the solar forcing than in the volcanic forcing. On the other hand, the BU signal among all layers is more persistent than the volcanic imprint due to the lack of "peaks" of activity. Still, the BU scenario is only the second strongest contributor to changes in the deep-layer ocean heat content, ranging behind the volcanic eruptions. One should note especially that while the uppermost layers of the VOLC experiment recover quite quickly (Fig. 5c, green curve), the signal stays memorized in the ocean, being rapidly transported into deeper layers (Fig. 5c, black curve).

Globally, a superrecovery of OHC during the 1820s is simulated for the VOLC experiment: this positive anomaly can be explained when focusing on the Bering Sea region (Fig. 5d), which can explain more than half of the global ocean heat content increase by the volcanic contribution.

Stenchikov et al. (2009) also investigated the influence of the Tambora eruption on the ocean. For all layers our simulated $\mathrm{OHC}$ anomaly is more pronounced, which can be explained by the lack of the 1809 volcanic eruption in the work of Stenchikov et al. (2009), but also by the fact that 

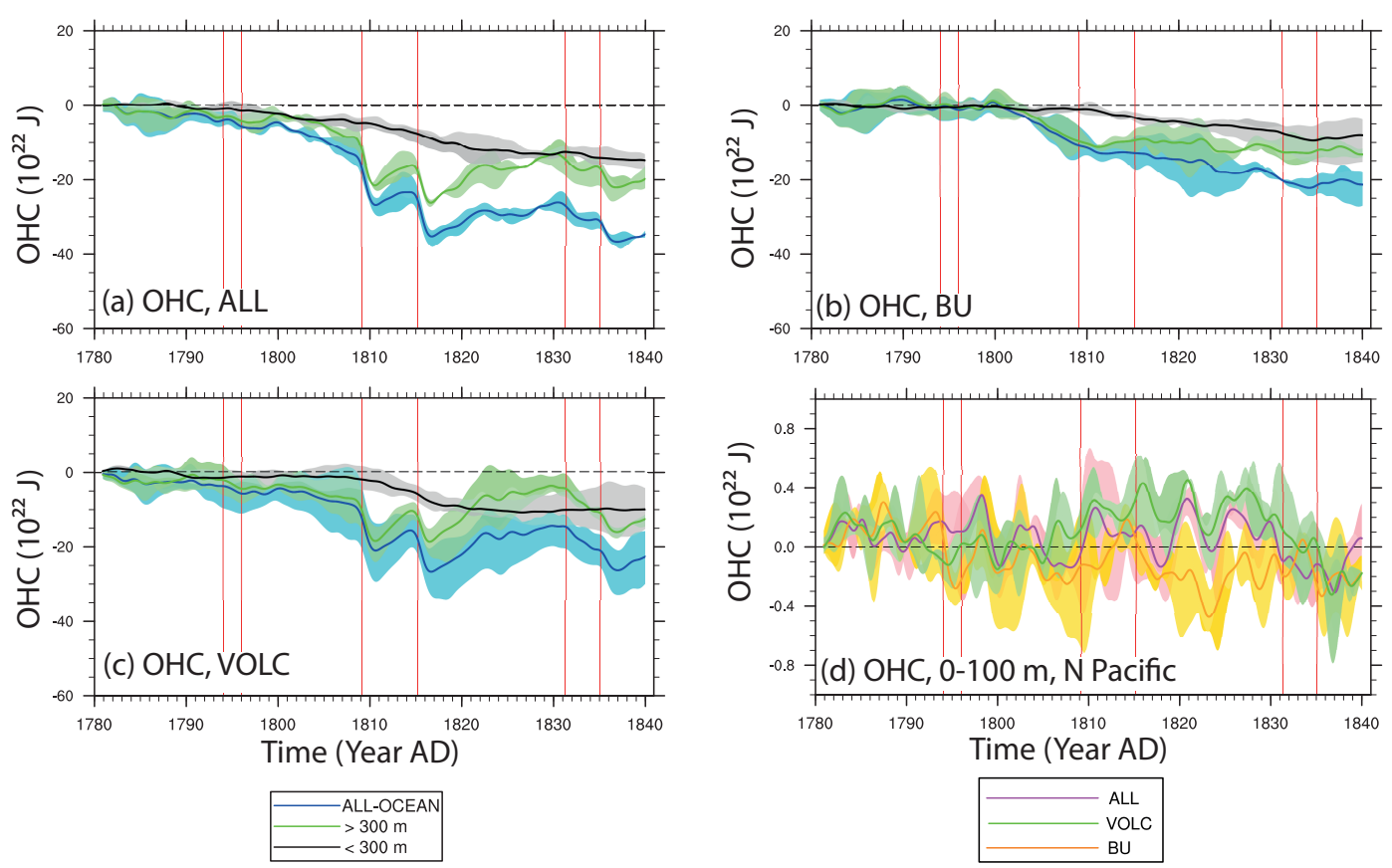

Fig. 5. Ensemble mean of detrended global ocean heat content (OHC) anomalies relative to CTRL1780, plotting technique analog to Stenchikov et al. (2009). For (a)-(c) the black curve shows global total OHC (0-6020 m), the green curve global OHC of the top $300 \mathrm{~m}$, the blue curve global OHC of the layers below 300 m (300-6020 m). (a) For ALL; (b) BU; (c) VOLC. (d) Ensemble mean of local OHC anomalies relative to CTRL1780 for the layers between 0 and $100 \mathrm{~m}$ in depth for the northern Pacific, Bering Sea region. Envelope shows the min/max values. Red vertical lines highlight the years in which a volcanic eruption occurred.

the Tambora eruption in our study has a larger radiative impact on the SH (and thus on the oceans) than in Stenchikov et al. (2009). The half-lives of the signals, however, are comparable to each other (Stenchikov et al., 2009: 16 years for 0.5 times the total OHC recovery. VOLC-experiment: 13 years needed for 0.45 times the total OHC recovery). The imprint of the lower OHC of Stenchikov et al. (2009) seems, however, to be much smaller than ours $\left(10 \times 10^{22} \mathrm{~J}\right.$ versus $\left.5.5 \times 10^{22} \mathrm{~J}\right)$, even if one would subtract the effect of the 1809 volcano in our sensitivity study. A possible explanation would be a faster deep water formation in MPI-OM than in CM2.1. This goes however beyond the scope of this work.

As neither the EPP nor the TD curves show large significant changes in the OHC (Fig. S5 in the Supplement), we conclude that although volcanic eruptions most likely kicked off the colder DM period, it was the reduction in the radiation with $\lambda>250 \mathrm{~nm}$ that maintained the low temperatures until the late 1830 s.

\subsection{Comparison to proxies}

Back in the past, regular reliable temperature measurements were only done in some specific locations, especially in Europe, with some station records starting around 1750 (Jones et al., 2001). Further back, one has to rely on proxy-based reconstructions. Different techniques and sources for $2 \mathrm{~m}$ temperature reconstructions are available, and the absolute values and variability amplitudes differ considerably from one to another data set. Most of the proxy data originate from tree rings. Not all techniques of tree ring-based (also known as "dendrochronological") temperature reconstructions are generally accepted by the scientific community (e.g., Cecile et al., 2013). Furthermore, there is an ongoing discussion if dendrochronological proxies are at all a good basis for robust reconstructions of temperature anomalies during volcanic active periods (e.g., Tambora, 1815-1816, see also Mann et al., 2012; Anchukaitis et al., 2012). Moreover, the exact dating may not always be accurate enough to match exactly a specific (e.g., volcanic) event due to proximity effects ("wrong" exposition of the tree in that particular year, e.g., in the shade). Here, we use the best-known NH temperature reconstructions published in the IPCC (2007), in order to allow comparison with other, similar modeling studies (e.g., Wagner and Zorita, 2005). We focus on NH temperature reconstructions since the density of proxy data is higher over the $\mathrm{NH}$ than over the $\mathrm{SH}$ and, therefore, $\mathrm{NH}$ data are expected to be more reliable. In Fig. S4 in the Supplement, the five different reconstructions of the $\mathrm{NH}$ temperatures used in this work are illustrated (Jones et al., 2001; Esper et al., 2002; D'Arrigo et al., 2006; Briffa et al., 2001; Mann et al., 1999).

In Fig. 6, the temperature evolution of the $\mathrm{NH} 2 \mathrm{~m}$ temperatures of the ALL, VOLC and BU experiments is compared to reconstructions, represented by a grey envelope. ENSO events monitored by the Niño 3.4 index are not shown. Yet, it 
still should be stated that most (over $70 \%$ ) of the events differ from one sensitivity experiment to another with a time lapse of \pm 1 year. However, in the periods of interest, which are discussed later in this section, the ENSO events of BU and VOLC happened at \pm the same period. The general anomaly pattern shown for the ALL experiment, which shows positive anomalies until the beginning of the 19th century, followed by a strong cooling between 1810 and 1820 , a warmer period in the 1820s and a further temperature minimum around 1835 agree very well with the reconstructed temperatures.

The first 30 years of the ALL time series are characterized by a slight temperature decrease, overlain by the 11-year solar cycle. As obvious from the sensitivity run BU, the temperatures follow the decline in solar irradiance of the Shapiro et al. (2011) forcing (Fig. 6, top panel). The cooling after the two smaller volcanic eruptions in the 1790s overcompensates the pure solar signal. While most of the reconstructions also show a 11 year-like cycle (Fig. S6 in the Supplement), the dating of the minima and maxima differs among the data sets, leading to a rather diffuse picture.

Starting from around 1805 until 1816 both the reconstructions and the modeled temperatures show a strong cooling by up to $0.6 \mathrm{~K}$. During that period, the ALL experiment is in very good agreement with the composite of the reconstructions, although a slight overestimation of the 1809 volcanic induced cooling in 1811-1812 is visible. After the two major volcanic eruptions in 1809 and 1815, the temperatures in the ALL experiment show a clear recovery until the year 1826. A very similar behavior is observed in the reconstructions, although the warming in the $1820 \mathrm{~s}$ is stronger than in the ALL simulation. As can be seen from the BU and VOLC sensitivity runs, the simulated temperature behavior can be explained as a combination of solar and volcanic effects: the BU experiment shows that the solar-only driven cooling starts already around 1803 , but the overall cooling is slightly postponed by a compensating warming by the earlier volcanic eruptions. The eruption of Mt. Tambora in 1815 overcompensates the solar-induced warming after 1810 , leading to a temperature minimum around 1816/1817, while the solar minimum around $1822(\mathrm{BU})$ prevents a more pronounced warming during the 1820 s, as visible in the VOLC model experiment.

The two volcanic eruptions of 1831 and 1835 with a predominant $\mathrm{NH}$ aerosol loading are followed by a second pronounced cold period, which is visible in the model simulations as well as in the reconstructions. Also, the simulated amplitude of this cooling, at $0.3-0.4 \mathrm{~K}$, is similar to the reconstructions.

Finally, the model simulation shows a recovery from the cold anomaly after 1836 , which can be explained by a general increase in solar irradiance at the end of the DM as well as dilution and removal of volcanic aerosols in the stratosphere. The warming is also found in the reconstructions.

It should be mentioned that the separation of solar and volcanic effects as done in BU and VOLC neglects nonlinear feedbacks. Nevertheless, we conclude that only the

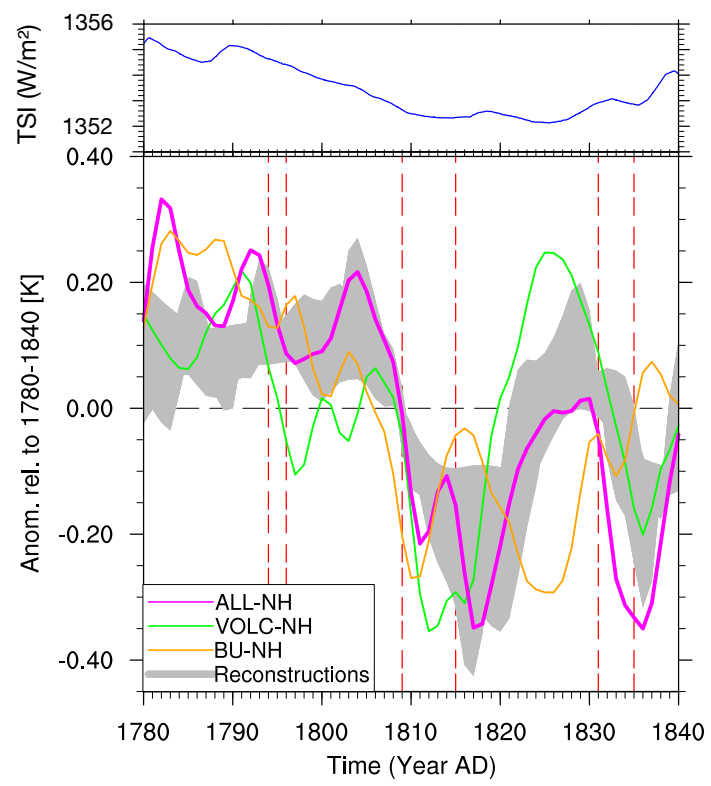

Fig. 6. Top panel: total solar irradiance from the Shapiro et al. (2011) forcing. Lower panel: model comparison with five NH temperature reconstructions of the IPCC AR4 (averaged). Magenta, green and orange lines are model curves, the grey envelope the composite of a range of tree ring-based reconstructions. Magenta thick: ensemble mean of NH temperatures (ALL-NH). Green: same, but for the VOLC experiment (VOLC-NH). Orange: same, but for the $\mathrm{BU}$ experiment (BU-NH). Grey region: envelope of the five $\mathrm{NH}$ temperature reconstructions plotted in Fig. S2 in the Supplement. Smoothing of the model results: Gaussian 3 years FWHM, centered on year 1 . Red vertical dashed lines highlight the years in which a volcanic eruption occurred.

combination of both volcanic events and BU decrease is able to reproduce the reconstructed temperature patterns. Moreover, we suggest that a solar-only driven DM would have induced two cold periods in the 1810s and 1820s. Those were overcompensated by a strong VOLC warming signal in the ALL temperature pattern.

\subsection{Precipitation and tropospheric circulation}

Figure 7 illustrates the absolute difference in seasonal averaged precipitation (JJA and DJF) for the ALL and VOLC run relative to the CTRL1780 constant forcing run. As can be recognized, the intertropical convergence zone (ITCZ) is shifted northwards to the equatorial Atlantic. Furthermore, a sharp decrease in precipitation both during the boreal summer and winter is modeled over the Pacific warm pool region, eastern Central America, and the maritime continent.

An interesting feature is the strong increase in precipitation over the Himalayan region as well as over the eastern part of the Indian Ocean. The surplus of precipitation in the Himalayan region is due to an increased northeasterly flow, coming from a northward shift of the ITCZ. In contrast, the precipitation anomaly over the western Pacific is related to 

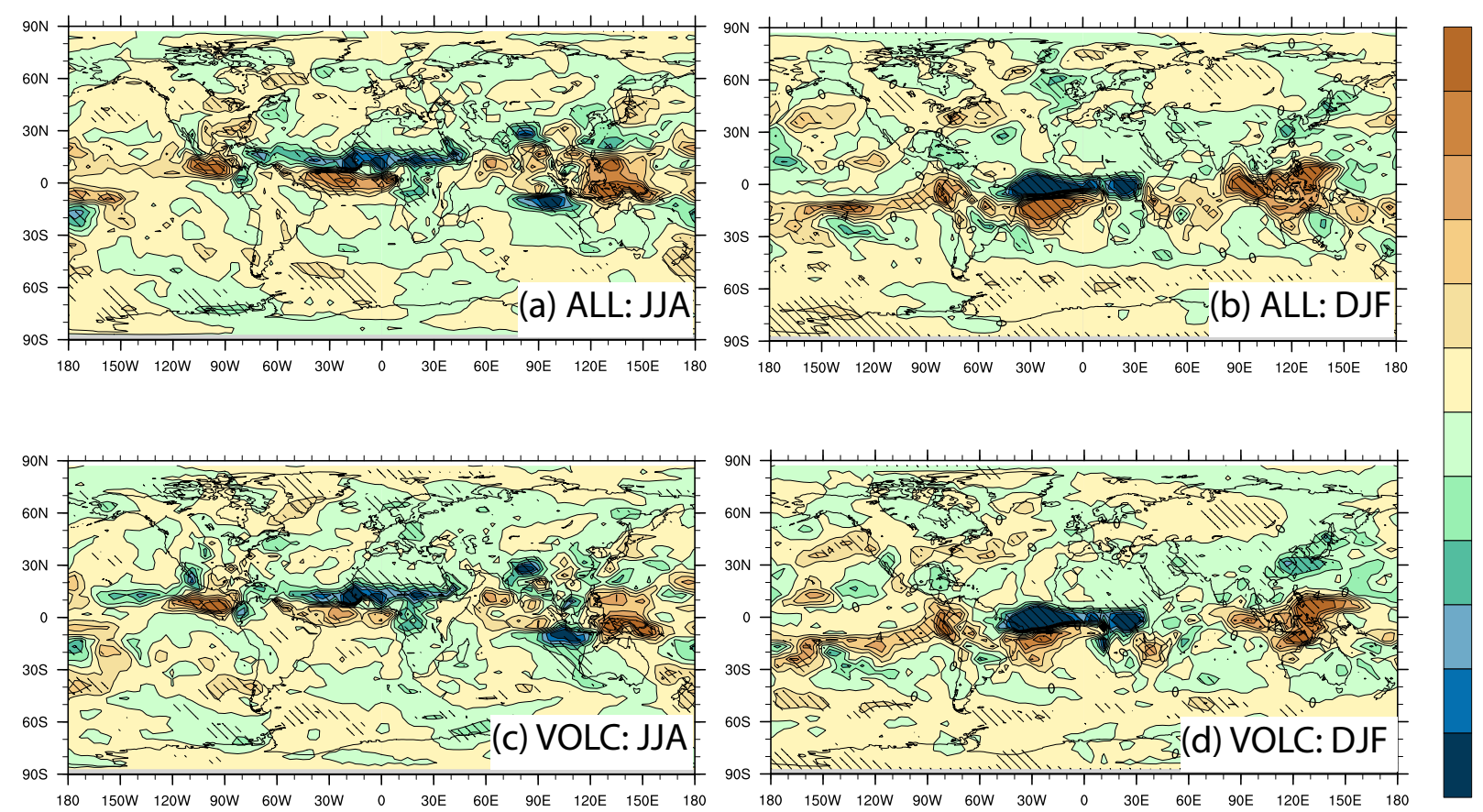

Fig. 7. (a) Ensemble mean of precipitation anomalies, averaged over the 1805-1825 period for the ALL run, JJA season. (b) Same for the DJF season. (c) Same for the VOLC run, JJA season. (d) Same for the VOLC run, DJF season. For all plots, dashed areas show significant changes in a $10 \% t$ test.

a decrease in sea surface temperatures in the El Niño 3 region, which is consistent with reduced evaporation, modified circulation and significant change in the ENSO signal, also impacting - via the atmosphere the precipitation patterns in the Indopacific region - corresponding to the mechanism presented in McGregor and Timmermann (2011). The decomposition of the ALL forcing plot into the four different forcing factors (EPP, $\lambda<250 \mathrm{~nm}, \lambda>250 \mathrm{~nm}$ and VOLC) shows that neither the solar forcing $(\lambda<250 \mathrm{~nm}, \lambda>250 \mathrm{~nm})$ nor the energetic particles significantly influence the seasonal or annual precipitation patterns. Hence, only the volcanic run is illustrated here (Fig. 7c and d) as it is the only run that shows a very similar precipitation anomaly pattern as in the ALL run.

A possible explanation for those precipitation anomalies lies both in the modified strength and width of the Hadley and Ferrel cells. In Fig. 8, the mass stream function (MSF) anomalies of the ALL and VOLC runs with respect to the CTRL1780 run are illustrated. During the boreal summer season (JJA), the upper branch of the Hadley cell is significantly weakened (Fig. 8a) - most probably due to the volcanic eruptions (Fig. 8c). Moreover, the Hadley cell expands in a northward direction (sharp decrease in the MSF field in Fig. $8 \mathrm{a}$ and $\mathrm{c}$ at $20^{\circ} \mathrm{N}$, meaning that the background climatology illustrated as contour lines would expand towards the $\mathrm{NH}$ ). During the winter season (DJF), we find a significant weakening of the Hadley cell (Fig. 8b and d) and a weak yet significant decrease in the Southern Hemispheric Ferrel cell.
The sizes of the cells are not significantly modified during the boreal summer season.

A similar signal has been found in Wegmann et al. (2013), who investigated the temperature and precipitation patterns after volcanic eruptions in preindustrial times. They concluded that a changed monsoon pattern and a modified behavior of the tropospheric circulation cells right after the volcanic eruptions is able to modify the global circulation, influencing short-term (some years) climate patterns over continental Europe. Although our seasonal precipitation signal is rather weak over Europe, we investigate the short-term climate pattern changes right after the different tropical volcanic eruptions $(1810,1816,1832,1836)$. Over Europe, the boreal winter SLP field (Fig. 3d) seems to switch to a more NAOplus-like situation, facilitating the transport of moist air from the Atlantic to the British islands and further to Scandinavia, while continental Europe stays in the slight influence of the anticyclonic pattern of the Azores. This NAOplus-like pattern influences the precipitation distribution, triggering a significant decrease over continental Europe and a slight increase over the British islands (Fig. 3f). The temperatures do change as well (Fig. 3b), but only marginally over continental Northern Europe, and show a slightly positive anomaly, according to the known "winter warming pattern" (see, e.g., Robock and Mao, 1992; Kirchner et al., 1999; Luterbacher et al., 2004). These results are in agreement to the work of, e.g., Iles et al. (2013), which found dryer winters and wetter summers after volcanic eruptions, as we do. During the 

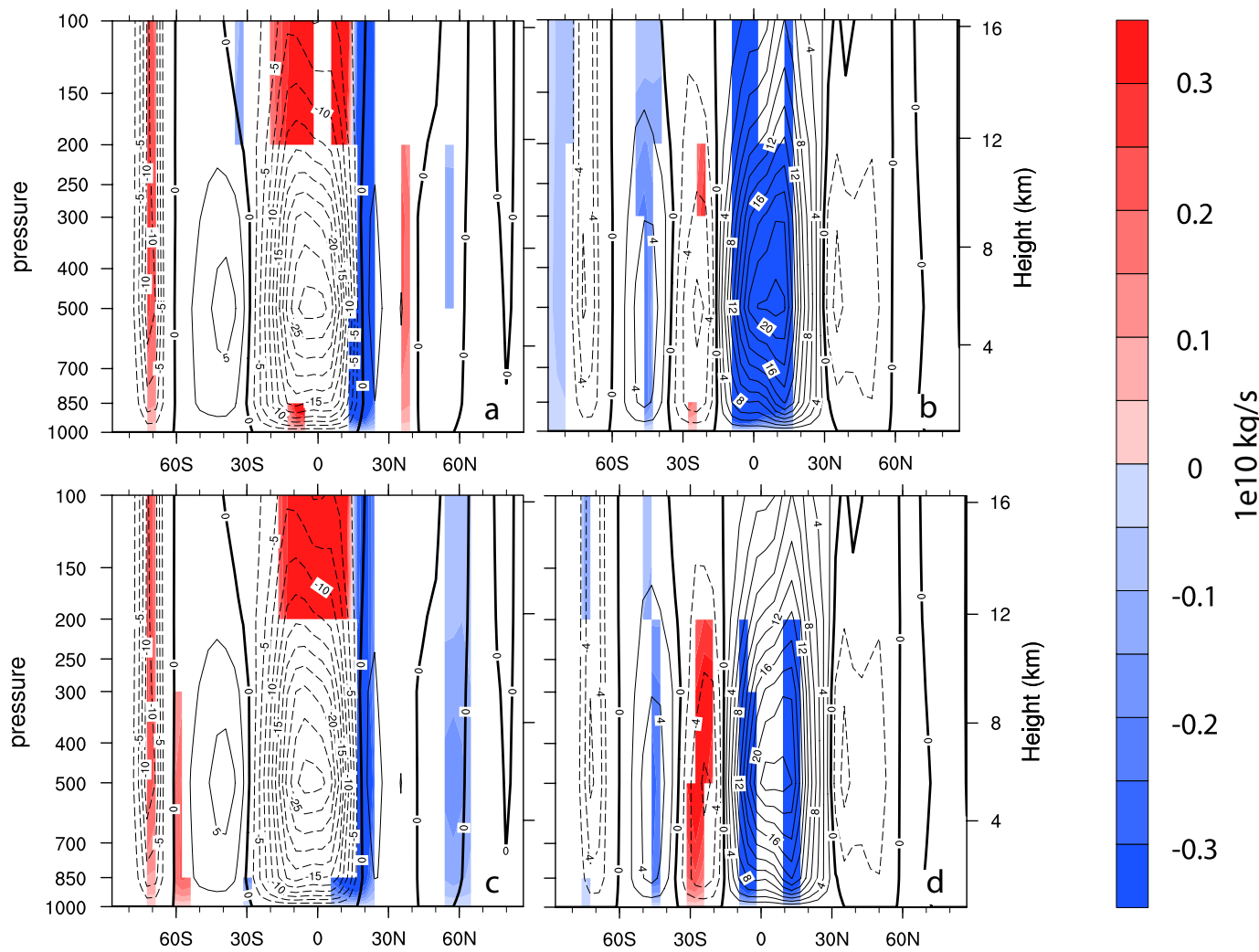

Fig. 8. (a) Ensemble mean of mass stream function anomalies, averaged over the 1805-1825 period for the ALL run, JJA season. (b) Same for the DJF season. (c) Same, but for the VOLC run, JJA season. (d) Same, but for the VOLC run, DJF season. For all plots, colored areas show significant changes in a $10 \% t$ test. Black contour lines show the climatology for the two seasons.

summer seasons following strong volcanic eruptions, a cold anomaly signal is found (Fig. 3a), which is likely to be triggered by a significant low-pressure anomaly over continental Europe and the storm track region (Fig. 3c), leading to a signal resembling a wet anomaly over large parts of Europe (Fig. 3e).

\section{Conclusions}

We have performed a series of sensitivity experiments over the DM with an AO-CCM, varying successively the solar radiation with $\lambda<250 \mathrm{~nm}$, the solar radiation with $\lambda>250 \mathrm{~nm}$, volcanic aerosols and energetic particles.

The results show that volcanic eruptions alone cannot explain the long-lasting negative surface air temperature anomaly during the DM found in different $\mathrm{NH}$ temperature reconstructions. Yet, while the long-term negative temperature trend in the DM can be explained by the "bottom-up" approach when reducing only radiation with $\lambda>250 \mathrm{~nm}$, the latter cannot explain the short and strong temperatures dips right after the volcanic eruptions. On the other hand, the volcanic eruptions experiment exaggerates the recovery of the surface temperatures in the $1820 \mathrm{~s}$.
We thus conclude that volcanic eruptions might have triggered the cold period from 1809 on, but that this cold time was maintained after 1816 by a lower solar irradiance. Without the decrease in solar irradiance, our model suggests that temperatures would have recovered to pre-1809 temperatures from 1820 on, except in the deep-layer ocean, in which the volcanic signal seems to dominate over the solar signal.

The obtained results indicate that the strong solar irradiance changes suggested by Shapiro et al. (2011) do not cause unrealistically large surface temperature changes during the DM, but rather help to reach a good agreement between simulated and reconstructed temperatures. This result contradicts the conclusions of Feulner (2011), which found a very large disagreement between surface temperature reconstructions and their model simulations using the solar irradiance forcing from Shapiro et al. (2011). The differences between the two studies do not arise from the selected reconstructions. Muthers et al. (2014b) compared the temperature evolution of all our four transient simulation members (1600-2000) against the Frank et al. (2010) reconstructions used by Feulner (2011), and it is clear that even if all the reconstructions of Frank et al. (2010) would have been plotted in our Fig. 6, it would not have significantly changed the overall picture. One possible explanation for this 
discrepancy between the two studies is the complexity of the applied models. While Feulner (2011) used an earth system model of intermediate complexity, this study uses a much more interactive atmosphere-ocean chemistry model of high complexity.

Our model results suggest moreover that, without the two strong 1809 and 1815 volcanic eruptions, the NH would have suffered a very cold period in the 1820 s, possibly putting the majority of the Earth's inhabitants in a problematic situation. Only the "overcompensation" of the cold anomaly after 1816 by the VOLC scenario in the Bering Sea region seems to have prevented this solar-induced cool period.

Our sensitivity studies show that the solar influence on the tropospheric climate is related to the bottom-up mechanism, while the efficiency of the top-down mechanism is negligible. We do not see any significant manifestations of the topdown mechanism (cooling in the lower tropical stratosphere (Anet et al., 2013), modulation of the Hadley cell and surface temperature changes in the Northern Hemisphere during boreal winter). Moreover, the simulated wintertime warming over the northern land masses after the major volcanic eruptions is not well pronounced and only marginally significant. The reasons for the weak efficiency of the top-down mechanism in our results are not clear. It can be related to model deficiencies in the simulation of the vertical coupling, of the polar vortex state or the wave generation and propagation, which become especially apparent when looking at the weak TD/EPP response. For example, Muthers et al. (2014a) showed that the efficiency of the top-down mechanism depends strongly on the climatological state of the simulated polar vortex. Further analysis should be done to understand whether the simulated polar vortex during the DM is too weak or too strong. It is moreover very possible that an interactive ocean damps the top-down and winter warming signal disproportionally, so that the signal disappears in the rather high noise of the NH temperature signal. The underestimation of the solar UV irradiance changes suggested by Shapiro et al. (2011) in comparison with the latest satellite measurements (Ermolli et al., 2013) could also be a reason, because a stronger UV forcing can make the top-down mechanism more efficient (see, e.g., Ineson et al., 2011). The other unexpected result is the weak influence of energetic particles, which can be explained by the absence of ozone response to the effects of low-energy electrons discussed by Anet et al. (2013) and probably some compensation between enhanced ionization by GCR and depressed ionization by electrons and protons during the DM.

We also show that due to volcanic eruptions, the hydrological cycle can be perturbed as such to decelerate the Hadley and Ferrel cells for timescales of 1-3 years. At the same time, the NAO is pushed into a NAOplus-like phase in the winters following a volcanic eruption, leading to an increase in precipitation in northern Europe and a negative precipitation anomaly in southern Europe. Still, the precipitation anomaly is weaker than in the other publications cited in our manuscript.

It is possible that our chosen timing in the volcanic forcing data (date of the year) of the 1809 and 1831 eruptions is wrong. This could of course influence the results discussed in the manuscript, as the timing (in the year) of the eruption determines in which hemisphere most of the volcanic aerosol will be transported. Moreover, characteristics of the stratospheric dynamics in the DM - such as the QBO, which was nudged in our model and in the volcanic forcing calculation - are only reconstructed, and not observed. Also here, a certain margin of uncertainty persists, possibly influencing our results. The anomalies in temperature and precipitation might be more significant, as only two months of difference in the volcanic eruption lead to different results (as stated and shown in, e.g., Kravitz and Robock, 2011; Toohey et al., 2011; Driscoll et al., 2012).

This is also a reason why the upwelling mechanism in the Bering Sea region leading to the overcompensation-like temperature signal after the strong volcanic eruptions should be considered with interest, but with care. A different timing of the eruptions might lead to a different reaction not only of the tropospheric circulation cells, but also of the ocean. Also, internal variability might be a reason for the simulated response of the Bering Sea region. Also, internal variability might influence the simulated response of the Bering Sea region: Zanchettin et al. (2013) showed that internal climate variability can strongly spread the simulated decadal climate response to a strong eruption, with individual realizations differing for up to $1 \mathrm{~K}$ in decadal $\mathrm{NH}$ temperature outputs during the first two decades after the 1815 Tambora eruption. A higher number of ensembles would consolidate our findings.

Future investigations should be done focusing on the downward propagation of the stratospheric perturbations in a model with prescribed sea surface temperatures versus a model with an interactive ocean. Future research should also investigate to what extent the impact of decreasing SEP/LEE efficiency can compensate for increasing GCR influences on regional temperature changes. The upwelling signal in the Bering Sea region should be confirmed with a different timing of the volcanic eruptions and another model setup. Moreover, the statistical testing procedures should be consolidated by increasing the number of ensemble members.

\section{Supplementary material related to this article is

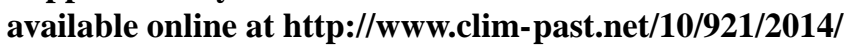 cp-10-921-2014-supplement.zip.}

Acknowledgements. Support by the Swiss National Science Foundation under grant CRSI122-130642 (FUPSOL) is gratefully acknowledged. Moreover, we would like to acknowledge the NCL plotting tool (NCAR/CISL/VETS, 2012), which enabled 
efficient and appealing visualization of the model data. E. Rozanov, A. I. Shapiro, and W. Schmutz thank COST Action ES1005 TOSCA (http://www.tosca-cost.eu) for the support and fruitful discussions. Many thanks go also to $\mathrm{H}$. Wanner (Oeschger Centre for Climate Change Research, Bern) for the efficient, creative and enthusiastic discussions. This paper profited from discussions during the PAGES/FUPSOL Workshop in 2012. Finally, we would like to thank the two anonymous reviewers for their valuable comments and Eduardo Zorita for editing.

Edited by: E. Zorita

\section{References}

Adams, J. B., Mann, M. E., and Ammann, C. M.: Proxy evidence for an El Niño-like response to volcanic forcing, Nature, 426, 274-278, doi:10.1038/nature02101, 2003.

Anchukaitis, K. J., Breitenmoser, P., Briffa, K. R., Buchwal, A., Büntgen, U., Cook, E. R., D’Arrigo, R. D., Esper, J., Evans, M. N., Frank, D., Grudd, H., Gunnarson, B. E., Hughes, M. K., Kirdyanov, A., Korner, C., Krusic, P. J., Luckman, B., Melvin, T. M., Salzer, M. W., Shashkin, A. W., Timmreck, C., Vaganov, E. A., and Wilson, R. J. S.: Tree rings and volcanic cooling, Nat. Geosci., 5, 836-837, doi:10.1038/ngeo1645, 2012.

Anet, J. G., Muthers, S., Rozanov, E., Raible, C. C., Peter, T., Stenke, A., Shapiro, A. I., Beer, J., Steinhilber, F., Brönnimann, S., Arfeuille, F., Brugnara, Y., and Schmutz, W.: Forcing of stratospheric chemistry and dynamics during the Dalton Minimum, Atmos. Chem. Phys., 13, 10951-10967, doi:10.5194/acp13-10951-2013, 2013

Arfeuille, F., Weisenstein, D., Mack, H., Rozanov, E., Peter, T., and Brönnimann, S.: Volcanic forcing for climate modeling: a new microphysics-based data set covering years 1600-present, Clim. Past, 10, 359-375, doi:10.5194/cp-10-359-2014, 2014.

Baumgaertner, A. J. G., Jöckel, P., and Brühl, C.: Energetic particle precipitation in ECHAM5/MESSy1 - Part 1: Downward transport of upper atmospheric $\mathrm{NO}_{\mathrm{x}}$ produced by low energy electrons, Atmos. Chem. Phys., 9, 2729-2740, doi:10.5194/acp-92729-2009, 2009.

Briffa, K. R., Osborn, T. J., Schweingruber, F. H., Harris, I. C., Jones, P. D., Shiyatov, S. G., and Vaganov, E. A.: Low-frequency temperature variations from a northern tree ring density network, J. Geophys. Res., 106, 2929-2941, doi:10.1029/2000JD900617, 2001.

Brönnimann, S., Annis, J. L., Vogler, C., and Jones, P. D.: Reconstructing the quasi-biennial oscillation back to the early 1900s, Geophys. Res. Lett., 34, L22805, doi:10.1029/2007GL031354, 2007

Brugnara, Y., Brönnimann, S., Luterbacher, J., and Rozanov, E.: Influence of the sunspot cycle on the Northern Hemisphere wintertime circulation from long upper-air data sets, Atmos. Chem. Phys., 13, 6275-6288, doi:10.5194/acp-13-6275-2013, 2013.

Calisto, M., Usoskin, I., Rozanov, E., and Peter, T.: Influence of Galactic Cosmic Rays on atmospheric composition and dynamics, Atmos. Chem. Phys., 11, 4547-4556, doi:10.5194/acp-114547-2011, 2011.
Cecile, J., Pagnutti, C., and Anand, M.: A likelihood perspective on tree-ring standardization: eliminating modern sample bias, Clim. Past Discuss., 9, 4499-4551, doi:10.5194/cpd-9-44992013, 2013.

Crowley, J.: Causes of climate change over the past 1000 years, Science, 289, 270-277, 2000.

D'Arrigo, R., Wilson, R., and Jacoby, G.: On the long-term context for late twentieth century warming, J. Geophys. Res., 111, D03103, doi:10.1029/2005JD006352, 2006.

Driscoll, S., Bozzo, A., Gray, L. J., Robock, A., and Stenchikov, G.: Coupled Model Intercomparison Project 5 (CMIP5) simulations of climate following volcanic eruptions, J. Geophys. Res.Atmos., 117, D17105, doi:10.1029/2012JD017607, 2012.

Egorova, T., Rozanov, E., Zubov, V., and Karol, I.: Model for Investigating Ozone Trends (MEZON), Seria Fizika Atmosfery i Okeana, 39, translated by MAIK "Nauka/Interperiodica" (Russia), Izvestiia Akademii Nauk SSSR, 39, 310-326, 2003.

Egorova, T., Rozanov, E., Manzini, E., Haberreiter, M., Schmutz, W., Zubov, V., and Peter, T.: Chemical and dynamical response to the 11-year variability of the solar irradiance simulated with a chemistry-climate model, Geophys. Res. Lett., 31, L06119, doi:10.1029/2003GL019294, 2004

Ermolli, I., Matthes, K., Dudok de Wit, T., Krivova, N. A., Tourpali, K., Weber, M., Unruh, Y. C., Gray, L., Langematz, U., Pilewskie, P., Rozanov, E., Schmutz, W., Shapiro, A., Solanki, S. K., and Woods, T. N.: Recent variability of the solar spectral irradiance and its impact on climate modelling, Atmos. Chem. Phys., 13, 3945-3977, doi:10.5194/acp-13-3945-2013, 2013.

Esper, J., Cook, E. R., and Schweingruber, F. H.: Lowfrequency signals in long tree-ring chronologies for reconstructing past temperature variability, Science, 295, 2250-2253, doi:10.1126/science.1066208, 2002.

Etheridge, D., Steele, L., Langenfelds, R., Francey, R., Barnola, J., and Morgan, V.: Natural and anthropogenic changes in atmospheric $\mathrm{CO}_{2}$ over the last 1000 years from air in Antarctic ice and firn, J. Geophys. Res., 101, 4115-4128, doi:10.1029/95JD03410, 1996.

Etheridge, D. M., Steele, L. P., Francey, R. J., and Langenfelds, R. L.: Atmospheric methane between 1000 A.D. and present: Evidence of anthropogenic emissions and climatic variability, J. Geophys. Res., 103, 15979-15993, doi:10.1029/98JD00923, 1998.

Ferretti, D., Miller, J., White, J., Etheridge, D., Lassey, K., Lowe, D., Meure, C., Dreier, M., Trudinger, C., Van Ommen, T., and Langenfelds, R.: Unexpected changes to the global methane budget over the past 2000 years, Science, 309, 1714-1717, doi:10.1126/science.1115193, 2005.

Feulner, G.: Are the most recent estimates for Maunder Minimum solar irradiance in agreement with temperature reconstructions?, Geophys. Res. Lett., 38, L16706, doi:10.1029/2011GL048529, 2011.

Finlay, C. C., Maus, S., Beggan, C. D., Bondar, T. N., Chambodut, A., Chernova, T. A., Chulliat, A., Golovkov, V. P., Hamilton, B. Hamoudi, M., Holme, R., Hulot, G., Kuang, W., Langlais, B., Lesur, V., Lowes, F. J., Lühr, H., Macmillan, S., Mandea, M., McLean, S., Manoj, C., Menvielle, M., Michaelis, I., Olsen, N., Rauberg, J., Rother, M., Sabaka, T. J., Tangborn, A., TøffnerClausen, L., Thebault, E., Thomson, A. W. P., Wardinski, I., Wei, Z., and Zvereva, T. I.: International Geomagnetic Reference 
Field: the eleventh generation, Geophys. J. Int., 183, 1216-1230, doi:10.1111/j.1365-246X.2010.04804.x, 2010.

Fischer, E. M., Luterbacher, J., Zorita, E., Tett, S. F. B., Casty, C., and Wanner, H.: European climate response to tropical volcanic eruptions over the last half millennium, Geophys. Res. Lett., 34, L05707, doi:10.1029/2006GL027992, 2007.

Forster, P. M., Fomichev, V. I., Rozanov, E., Cagnazzo, C., Jonsson, A. I., Langematz, U., Fomin, B., Iacono, M. J., Mayer, B., Mlawer, E., Myhre, G., Portmann, R. W., Akiyoshi, H., Falaleeva, V., Gillett, N., Karpechko, A., Li, J., Lemennais, P., Morgenstern, O., Oberländer, S., Sigmond, M., and Shibata, K.: Evaluation of radiation scheme performance within chemistry climate models, J. Geophys. Res., 116, D10302, doi:10.1029/2010JD015361, 2011.

Frank, D. C., Esper, J., Raible, C. C., Büntgen, U., Trouet, V., Stocker, B., and Joos, F.: Ensemble 25 reconstruction constraints on the global carbon cycle sensitivity to climate, Nature, 463, 527-530, doi:10.1038/nature08769, 2010.

Gao, C., Robock, A., and Ammann, C.: Volcanic forcing of climate over the past 1500 years: An improved ice core-based index for climate models, J. Geophys. Res., 113, D23111, doi:10.1029/2008JD010239, 2008.

Giorgetta, M.: Der Einfluss der quasi-zweijaehrigen Oszillation: Modellrechnungen mit ECHAM4, Max-Planck-Institut für Meteorologie, Hamburg, Examensarbeit Nr. 40, MPI-Report 218, 1996

Hagemann, S.: An improved land surface parameter dataset for global and regional climate models, Max-Planck-Institut für Meteorologie, Hamburg, 2002.

Hagemann, S., Botzet, M., Dümenil, L., and Machenhauer, B.: Derivation of global GCM boundary conditions from $1 \mathrm{~km}$ land use satellite data, Max-Planck-Institut für Meteorologie, Hamburg, 1999.

Haigh, J. D.: The Impact of Solar Variability on Climate, Science, 272, 981-984, doi:10.1126/science.272.5264.981, 1996.

Harington, C.: The Year without a Summer, in: World Climate in 1816, edited by: Harington, C., Canadian Museum of Nature, Ottawa, 1992.

Iles, C. E., Hegerl, G. C., Schurer, A. P., and Zhang, X.: The effect of volcanic eruptions on global precipitation, J. Geophys. Res., 118, 8770-8786, doi:10.1002/jgrd.50678, 2013.

Ineson, S., Scaife, A. A., Knight, J. R., Manners, J. C., Dunstone, N. J., Gray, L. J., and Haigh, J. D.: Solar forcing of winter climate variability in the Northern Hemisphere, Nature, 4, 753-757, doi:10.1038/NGEO1282, 2011.

IPCC - Intergovernmental Panel on Climate Change: Climate change 2007: The Physical Science Basis, Contribution of Working Group I to the Fourth Assessment Report of the Intergovernmental Panel on Climate Change, in: AR4, edited by: Solomon, S., Qin, D., Manning, M., Chen, Z., Marquis, M., Averyt, K., Tignor, H., and Miller, H., Cambridge University Press, Cambridge, UK and New York, NY, USA, 2007.

Jones, P. D., Ogilvie, A. E., Davies, T. D., and Briffa, K. R.: History and climate: memories of the future?, Springer, Berlin, 2001.

Kirchner, I., Stenchikov, G. L., Graf, H.-F., Robock, A., and Antuna, J. C.: Climate model simulation of winter warming and summer cooling following the 1991 Mount Pinatubo volcanic eruption, J. Geophys. Res., 104, 19039-19055, doi:10.1029/1999JD900213, 1999.
Kodera, K. and Kuroda, Y.: Dynamical response to the solar cycle, J. Geophys. Res., 107, 4749-4761, doi:10.1029/2002JD002224, 2002.

Kravitz, B. and Robock, A.: Climate effects of high-latitude volcanic eruptions: Role of the time of year, J. Geophys. Res., 116, D01105, doi:10.1029/2010JD014448, 2011.

Labitzke, K., Austin, J., Butchardt, N., Knight, J., Takahashi, M., Nakamoto, M., Nagashima, T., Haigh, J., and Williams, V.: The global signal of the 11-year solar cycle in the stratosphere: observations and models, J. Atmos. Sol.-Terr. Phy., 64, 203-210, doi:10.1016/S1364-6826(01)00084-0, 2002.

Luterbacher, J., Dietrich, D., Xoplaki, E., Grosjean, M., and Wanner, H.: European Seasonal and Annual Temperature Variability, Trends, and Extremes Since 1500, Science, 303, 1499-1503, doi:10.1126/science.1093877, 2004.

MacFarling-Meure, C., Etheridge, D., Trudinger, C., Steele, P., Langenfelds, R., Van Ommen, T., Smith, A., and Elkins, J.: Law Dome $\mathrm{CO}_{2}, \mathrm{CH}_{4}$ and $\mathrm{N}_{2} \mathrm{O}$ ice core records extended to 2000 years BP, Geophys. Res. Lett., 33, L14810, doi:10.1029/2006GL026152, 2006.

Mann, M., Bradley, S., and Hughes, M.: Northern hemisphere temperatures during the past millennium: inferences, uncertainties, and limitations, Geophys. Res. Lett., 26, 759-762, doi:10.1029/1999GL900070, 1999.

Mann, M. E., Fuentes, J. D., and Rutherford, S.: Underestimation of volcanic cooling in tree-ring-based reconstructions of hemispheric temperatures, Nat. Geosci., 5, 202-205, doi:10.1038/ngeo1394, 2012.

Marsland, S., Haak, H., Jungclaus, J., Latif, M., and Roske, F.: The Max-Planck-Institute global ocean/sea ice model with orthogonal curvilinear coordinate, Ocean Model., 5, 91-27, doi:10.1016/S1463-5003(02)00015-X, 2003.

McGregor, S. and Timmermann, A.: The effect of explosive tropical volcanism on ENSO, J. Climate, 24, 2178-2191, doi:10.1175/2010JCLI3990.1, 2011.

Meehl, G. A., Arblaster, J., Branstator, G., and Van Loon, H.: A coupled air-sea response mechanism to solar forcing in the Pacific region, J. Climate, 21, 2883-2897, doi:10.1175/2007JCLI1776.1, 2008.

Meehl, G. A., Arblaster, J. M., Matthes, K., Sassi, F., and van Loon, H.: Amplifying the Pacific Climate System Response to a Small 11-Year Solar Cycle Forcing, Science, 325, 1114-1118, doi:10.1126/science.1172872, 2009.

Muthers, S., Anet, J., Raible, C., Brönnimann, S., Rozanov, E., Arfeuille, F., Peter, T., Shapiro, A., Beer, J., Steinhilber, F., Brugnara, Y., and Schmutz, W.: Northern hemispheric winter warming pattern after tropical volcanic eruptions: Sensitivity to the ozone climatology, J. Geophys. Res.-Atmos., 119, 1340-1355, doi:10.1002/2013JD020138, 2014a.

Muthers, S., Anet, J., Raible, C., Brönnimann, S., Rozanov, E., Arfeuille, F., Peter, T., Shapiro, A., Beer, J., Steinhilber, F., Brugnara, Y., and Schmutz, W.: The coupled atmosphere-chemistryocean model SOCOL-MPIOM, Geosci. Model Dev. Discuss., 7, 3013-3084, doi:10.5194/gmdd-7-3013-2014, 2014b.

NCAR/CISL/VETS: The NCAR Command Language (Version 6.0.0) [Software], Boulder, USA, 2012.

Olson, D. W., Doescher, R. L., and Olson, M. S.: The blood-red sky of the scream, American Physical Society, Maryland, 13-14, 2004. 
Robertson, A., Overpeck, J., Rind, D., Mosley-Thompson, E., Zielinski, G., Lean, J., Koch, D., Penner, J., Tegen, I., and Healy, R.: Hypothesized climate forcing time series for the last 500 years, J. Geophys. Res.-Atmos., 106, 14783-14803, doi:10.1029/2000JD900469, 2001.

Robock, A.: Review of Year Without a Summer? World Climate in 1816, Climatic Change, 26, 105-108, 1994.

Robock, A.: Volcanic Eruptions and Climate, Rev. Geophys., 38, 191-219, doi:10.1029/1998RG000054, 2000.

Robock, A. and Mao, J.: Winter warming from large volcanic eruptions, Geophys. Res. Lett., 19, 2405-2408, doi:10.1029/92GL02627, 1992.

Robock, A. and Mao, J.: The volcanic signal in surface temperature observations, J. Climate, 8, 1086-1103, doi:10.1175/15200442(1995)008<1086:TVSIST>2.0.CO;2, 1995.

Roeckner, E., Baeuml, G., Bonaventura, L., Brokopf, R., Esch, M., Giorgetta, M., Hagemann, S., Kirchner, I., Kornblueh, L., Manzini, E., Rhodin, A., Schlese, U., Schulzweida, U., and Tompkins, A.: The atmospheric general circulation model ECHAM 5, PART I: Model description, Report No. 349, http://www.mpimet.mpg.de/fileadmin/publikationen/ Reports/max_scirep_349.pdf., Max-Plank-Institut für Meteorologie, Hamburg, 2003.

Rozanov, E. V., Schlesinger, M. E., Zubov, V., Yang, F., and Andronova, N. G.: The UIUC three-dimensional stratospheric chemical transport model: Description and evaluation of the simulated source gases and ozone, J. Geophys. Res., 104, 755-781, doi:10.1029/1999JD900138, 1999.

Rozanov, E. V., Egorova, T. A., Shapiro, A. I., and Schmutz, W. K.: Modeling of the atmospheric response to a strong decrease of the solar activity, Proc. Int. Astron. Union, 7, 215-224, doi:10.1017/S1743921312004863, 2012a.

Rozanov, E. V., Calisto, M., Egorova, T., Peter, T., and Schmutz, W.: Influence of the Precipitating Energetic Particles on Atmospheric Chemistry and Climate, Surv. Geophys., 33, 483-501, doi:10.1007/s10712-012-9192-0, 2012b.

Schraner, M., Rozanov, E., Schnadt Poberaj, C., Kenzelmann, P., Fischer, A. M., Zubov, V., Luo, B. P., Hoyle, C. R., Egorova, T., Fueglistaler, S., Brönnimann, S., Schmutz, W., and Peter, T.: Technical Note: Chemistry-climate model SOCOL: version 2.0 with improved transport and chemistry/microphysics schemes, Atmos. Chem. Phys., 8, 5957-5974, doi:10.5194/acp-8-59572008, 2008

Semeniuk, K., Fomichev, V. I., McConnell, J. C., Fu, C., Melo, S. M. L., and Usoskin, I. G.: Middle atmosphere response to the solar cycle in irradiance and ionizing particle precipitation, Atmos. Chem. Phys., 11, 5045-5077, doi:10.5194/acp-11-50452011, 2011.

Shapiro, A. I., Schmutz, W., Schoell, M., Haberreiter, M., and Rozanov, E.: NLTE solar irradiance modeling with the COSI code, Astron. Astrophys., 517, A48, doi:10.1051/00046361/200913987, 2010.

Shapiro, A. I., Schmutz, W., Rozanov, E., Schoell, M., Haberreiter, M., Shapiro, A. V., and Nyeki, S.: A new approach to the long-term reconstruction of the solar irradiance leads to large historical solar forcing, Astron. Astrophys., 529, A67, doi:10.1051/0004-6361/201016173, 2011.
Shindell, D., Schmidt, G., Miller, R., and Mann, M.: Volcanic and solar forcing of climate change during the preindustrial era, J. Climate, 16, 4094-4107, doi:10.1175/15200442(2003)016<4094:VASFOC>2.0.CO;2, 2000.

Sinnhuber, M., Nieder, H., and Wieters, N.: Energetic Particle Precipitation and the Chemistry of the Mesosphere/Lower Thermosphere, Surv. Geophys., 33, 1281-1334, doi:10.1007/s10712012-9201-3, 2012.

Solanki, S. K., Krivova, N. A., and Haigh, J. D.: Solar Irradiance Variability and Climate, Astron. Astrophys., 51, 311-351, doi:10.1146/annurev-astro-082812-141007, 2013.

Steinhilber, F., Abreu, J. A., and Beer, J.: Solar modulation during the Holocene, Astrophys. Space Sci., 4, 1-6, doi:10.5194/astra4-1-2008, 2008

Steinhilber, F., Beer, J., and Fröhlich, C.: Total solar irradiance during the Holocene, Geophys. Res. Lett., 36, L19704, doi:10.1029/2009GL040142, 2009.

Stenchikov, G., Robock, A., Ramaswamy, V., Schwarzkopf, M. D., Hamilton, K., and Ramachandran, S.: Arctic Oscillation response to the 1991 Mount Pinatubo eruption: Effects of volcanic aerosols and ozone depletion, J. Geophys. Res., 107, ACL 28-1ACL 28-16, doi:10.1029/2002JD002090, 2002.

Stenchikov, G., Delworth, T. L., Ramaswamy, V., Stouffer, R. J., Wittenberg, A., and Zeng, F.: Volcanic signals in oceans, J. Geophys. Res., 114, D16104, doi:10.1029/2008JD011673, 2009.

Stenke, A., Schraner, M., Rozanov, E., Egorova, T., Luo, B., and Peter, T.: The SOCOL version 3.0 chemistry-climate model: description, evaluation, and implications from an advanced transport algorithm, Geosci. Model Dev., 6, 1407-1427, doi:10.5194/gmd-6-1407-2013, 2013.

Toohey, M., Krüger, K., Niemeier, U., and Timmreck, C.: The influence of eruption season on the global aerosol evolution and radiative impact of tropical volcanic eruptions, Atmos. Chem. Phys., 11, 12351-12367, doi:10.5194/acp-11-12351-2011, 2011.

Valcke, S.: The OASIS3 coupler: a European climate modelling community software, Geosci. Model Dev., 6, 373-388, doi:10.5194/gmd-6-373-2013, 2013.

Varma, V., Prange, M., Lamy, F., Merkel, U., and Schulz, M.: Solarforced shifts of the Southern Hemisphere Westerlies during the Holocene, Clim. Past, 7, 339-347, doi:10.5194/cp-7-339-2011, 2011.

Varma, V., Prange, M., Spangehl, T., Lamy, F., Cubasch, U., and Schulz, M.: Impact of solar-induced stratospheric ozone decline on Southern Hemisphere westerlies during the Late Maunder Minimum, Geophys. Res. Lett., 39, L20704, doi:10.1029/2012GL053403, 2012

Wagner, S. and Zorita, E.: The influence of volcanic, solar and $\mathrm{CO}_{2}$ forcing on the temperatures in the Dalton Minimum (1790 1830): a model study, Clim. Dynam., 25, 205-218, 2005.

Wang, T., Otterå, O., Gao, Y., and Wang, H.: The response of the North Pacific Decadal Variability to strong tropical volcanic eruptions, Clim. Dynam., 39, 2917-2936, doi:10.1007/s00382012-1373-5, 2012.

Wegmann, M., Brönnimann, S., Bhend, J., Franke, J., Folini, D., Wild, M., and Luterbacher, J.: Volcanic influence on European summer precipitation though monsoons: Possible cause for "Years Without a Summer", J. Climate, doi:10.1175/JCLI-D-1300524.1, in press, 2013. 
Wolf, R.: Abstract of his latest results, Mon. Not. R. Astron. Soc., 21, 77, 1861.

Zanchettin, D., Timmreck, C., Graf, H.-F., Rubino, A., Lorenz, S., Lohmann, K., Krüger, K., and Jungclaus, J.: Bi-decadal variability excited in the coupled ocean-atmosphere system by strong tropical volcanic eruptions, Clim. Dynam., 39, 419-444, doi:10.1007/s00382-011-1167-1, 2012.
Zanchettin, D., Bothe, O., Graf, H. F., Lorenz, S. J., Luterbacher, J., Timmreck, C., and Jungclaus, J. H.: Background conditions influence the decadal climate response to strong volcanic eruptions, J. Geophys. Res.-Atmos., 118, 4090-4106, doi:10.1002/jgrd.50229, 2013. 